\title{
Optimization of medical waste recycling network considering disposal capacity bottlenecks under a novel coronavirus pneumonia outbreak
}

\author{
Xueyun Mei ${ }^{1} \cdot$ Hao Hao ${ }^{1} \cdot$ Yichen Sun ${ }^{1} \cdot$ Xinyang Wang ${ }^{1} \cdot$ Yanjun Zhou $^{1}$ \\ Received: 16 June 2021 / Accepted: 14 August 2021 / Published online: 3 September 2021 \\ (C) The Author(s), under exclusive licence to Springer-Verlag GmbH Germany, part of Springer Nature 2021
}

\begin{abstract}
The sudden outbreak and prolonged impact of the global novel coronavirus disease (COVID-19) epidemic has caused an increase in demand for medical products, such as masks and protective clothing, leading to an exponential increase in the generation of medical waste. As medical waste under the epidemic is highly infectious, it poses a great danger to human health. Therefore, with the proliferation of medical waste, it has become crucial to construct a reverse logistics recycling network that can handle medical waste quickly and efficiently. In this study, we construct a multi-period medical waste emergency reverse logistics network siting model with the objectives of minimum cost, minimum safety risk, and minimum time for the safe and quick disposal of medical waste. The model considers disposal capacity bottlenecks of existing facilities. Based on an empirical analysis using the COVID19 epidemic in New York City, USA, as a case study, we find that the use of a suitable number of synergistic facilities and the establishment of temporary medical waste disposal centers are viable options for handling the dramatic increase in medical waste during the peak of the COVID-19 epidemic.
\end{abstract}

Keywords Disposal capacity bottlenecks · COVID-19 · Mixed-integer nonlinear programming model · Emergency reverse logistics network $\cdot$ Third-order polynomial function $\cdot$ Safety risk

\section{Introduction}

According to Johns Hopkins University, as of March 24, 2021, there are more than 124 million confirmed cases of coronavirus of novel disease (COVID-19) and more than 2.73 million COVID-19-related deaths worldwide. This unprecedented public health crisis has placed a high demand on the level of medical care worldwide. According to the WHO (2020), upgrading healthcare delivery norms, large-scale research and development activities, and continuous adaptation of public policies have become important initiatives in response to this crisis. It has been accompanied by an exponential increase in the amount of disposable masks, protective clothing, goggles, gloves, and many

Responsible Editor: Lotfi Aleya

Hao Hao

hehao8888@sina.com

1 School of Economics and Management, Shanghai Polytechnic University, Shanghai 201209, China other types of medical waste (Sharma et al. 2020). At the peak of the outbreak in China from February 15 to March 15, 2020, Wuhan generated nearly 247 tons of medical waste per day, nearly six times more than it generated before the outbreak (Singh et al. 2020). Novel coronaviruses can survive for days on inanimate surfaces such as plastic, metal, and glass (Kampf et al. 2020). Failure to properly dispose of infectious medical waste not only poses a potential risk of environmental contamination to the government and the public (Hao et al. 2018a) but also leads to the spread of infectious diseases such as AIDS, cholera, typhoid, and respiratory complications, as well as exacerbates the spread of COVID-19 (Sarkodie and Owusu 2021). The United Nations Basel Convention on Transboundary Movements of Hazardous Wastes and their Disposal urges member states to treat medical waste generated during COVID-19 as an urgent and necessary public service event to minimize possible secondary effects on health and the environment (Singh et al. 2020).

In view of the dramatic increase in the amount of medical waste in a short period of time under the COVID-19 epidemic, 
this study establishes a medical waste recycling network considering bottlenecks in disposal capacity and aims to address the problem of siting medical waste recycling network facilities in an emergency situation. First, the network structure of medical waste recycling under the COVID-19 epidemic was constructed, including hospitals, sterilization transfer centers, domestic waste incineration centers (requisitioned), hazardous waste incineration centers (requisitioned), newly constructed temporary medical waste disposal centers, existing medical waste disposal centers, and harmless treatment centers. Second, based on the prediction of the number of patients in the next 3 months using a third-order polynomial function model, a multi-period medical waste emergency reverse logistics network siting model with the objectives of minimizing cost, minimizing safety risk, and minimizing time was established. In this study, the network design takes into account the construction cost of new temporary medical waste disposal centers set up to resolve disposal capacity bottlenecks, the acquisition cost of synergistic facilities such as incineration centers, the closure cost of new temporary medical waste disposal centers, and time urgency. It also regards traditional economic cost indicators such as transportation, operation, disposal, and disinfection costs according to the highly infectious nature of the medical waste. Taking into consideration all these costs and capacity bottlenecks, the model determines the appropriate location and flow rate in the medical waste recycling network.

The contributions of this study are as follows: (1) a generic emergency reverse logistics recycling network model adapted to infectious diseases is proposed. (2) The characteristics of the growth of medical waste amount during the COVID-19 epidemic period are considered. The construction and closure cost of new temporary medical waste disposal centers and sterilization transfer centers, the cost of collaborative disposal such as the requisition of incineration centers, and time urgency are estimated. (3) Taking into consideration the actual situation, the requisition of domestic waste incineration centers, hazardous waste incineration centers, and other synergistic facilities to dispose of medical waste reduces the construction and closure costs of new temporary medical waste disposal centers, while shortening the time to build new facilities and reducing the risk of infection. (4) Minimize safety risks including transportation and operation facility risks. (5) Through an empirical study of medical waste disposal under the COVID-19 outbreak in New York City, USA, the validity of the model is verified, and some management insights are provided to managers.

The rest of the paper is organized as follows: Based on the introduction of the literature review, the current status of research on reverse logistics networks is presented. Next, the model construction of the article is presented. Then based on the model built, an empirical analysis as well as a sensitivity analysis is conducted with New York
City, USA, as an example. Finally, the article is summarized.

\section{Literature review}

This study focuses on four aspects: reverse logistics network planning, emergency response network, medical waste reverse logistics recycling network, and emergency medical waste reverse logistics network under the COVID-19 epidemic. We will review related research on these aspects.

In terms of reverse logistics network planning, Stock (1992) first proposed the concept of reverse logistics, which is broadly defined to include all logistics activities related to resource conservation, recycling, replacement, reuse of materials, and disposal. Due to the lack of natural resources, environmental factors, and government regulations related to discarded products, recycling of products and materials is a growing concern (Wang et al. 2019a). Fleischmann et al. (2001) summarized the commonalities of product recycling reverse logistics and constructed a generalized facility siting model; he suggested that product recycling is largely dependent on the environment. Hao et al. (2017) proposed the concept of "fifth profit source," pointing out that the development of reverse logistics should focus not only on the economic benefits, but also on the environmental and social benefits, so as to promote the sustainable development of enterprises and realize circular economy. Sun and Da (2009) considered government subsidies, transportation discount problems, fixed cost saving rates, and minimum recovery rates, and used them to construct a mixed-integer nonlinear programming model. Choudhary et al. (2015) integrated the carbon footprint throughout the integrated forward and reverse logistics network, and established a mixed-integer programming model with the objective of minimizing the total cost. Ene and Öztürk (2015) and Xiao et al. (2019) established a multi-period mixed-integer programming model with the objectives of cost minimization and environmental impact minimization to solve the siting problem of end-of-life vehicle recycling network facilities. Zhou et al. (2015) constructed a multi-period multi-objective dynamic mixed-integer programming model by considering the social and economic benefits. Amin and Baki (2017) constructed a multi-objective mixedinteger programming model considering environmental factors, consumer markets, and recycling quantity uncertainty problems. Hajiaghaei-Keshteli and Fathollahi Fard (2018) constructed a multi-objective mixed-integer nonlinear programming model considering price discounts and index evaluation of sustainability to achieve a balanced maximization of economic, social, and environmental benefits. Most of the current reverse logistics network designs use mixed-integer programming models and some focus on green and social 
benefits; however, few models consider the safety and risk aspects.

With the frequent occurrence of natural disasters and public health events, emergency logistics networks have gradually become a focus of considerable research attention. However, there has been almost no research on emergency reverse logistics. Emergency logistics is mainly applied in various crisis mitigation activities such as pre-disaster rescue facility site selection, post-disaster material transportation distribution, and casualty transportation (Caunhye et al. 2012). RezaeiMalek et al. (2016) considered the storage time of predisaster perishable food and the uncertainty of demand quantity at each demand point, and constructed a new integrated network model to determine the location at which perishable commodity is required and quantity of storage in the predisaster period. Zhang et al. (2019) constructed a three-stage stochastic programming model with the objectives of minimizing transportation cost, unmet demand, and transportation time to solve the problems of facility location and resource allocation caused by primary and secondary disasters. Liu et al. (2020a) used influenza A (H1N1) in the Jiangsu province as an example and established an epidemic emergency logistics network optimization model based on service level. To design this model, they integrated the mobility characteristics of the population of the epidemic area, the population density characteristics of different epidemic areas, the secondary ring prevention strategy of government departments, the service radius limitation of emergency distribution, and other realistic factors.

In terms of medical waste reverse logistics recycling networks, Budak and Ustundag (2017) constructed a multi-product, multi-period mixed-integer linear programming model with the objective of cost minimization based on different types of medical waste. Alizadeh et al. (2020) developed a closed-loop supply chain model with the objectives of profit maximization, transport distance, and time minimization based on the infectious nature of medical waste and the capacity limitation of sterilization centers. Kargar et al. (2020a) constructed a multi-period mixed-integer linear programming model with the objectives of minimizing cost, selecting the best processing technology, and minimizing the total amount of medical waste stored in hospitals. The model was designed considering the problem of siting and routing of medical waste recycling network facilities under uncertain conditions. Wang et al. (2019b) developed a multi-objective multi-period mixed-integer programming model to solve the problem of siting medical waste recycling facilities by considering economic and environmental benefits. Huo and Guo (2020) constructed a sustainable medical waste recycling network with the objectives of minimizing cost, minimizing environmental impact, and maximizing social benefits in view of the uncertainty, multi-periodicity, and pollution of medical waste recycling. Expired drugs are also medical waste that can cause great harm to the human body and the environment. Wang and Huang (2015) considered the choice behavior of residents and introduced the incentive of government subsidy to recycling enterprises and recycling enterprises to residential areas; they constructed a bi-level programming model for the reverse logistics network of expired drugs. Jing and Chen (2015) constructed a reverse logistics network planning model for expired drugs with the objective of minimizing the total cost. Cao et al. (2017) constructed a multiperiod pharmaceutical reverse logistics network linkage model considering carbon emissions to solve the problem of recycling expired drugs or used medical devices; they used genetic algorithms for case analysis. Ahlaqqach et al. (2020) developed a closed-loop supply chain model for pharmaceuticals with mixed-integer nonlinear programming with the objectives of maximizing economic benefits, creating the most jobs, and minimizing transportation risks. From the aforementioned literature, it can be seen that most of the current studies on medical waste consider economic, environmental, multiproduct, and uncertainty factors and construct mixed-integer programming models. In this aspect too, it can be observed that very few studies have considered the possible infection risk (safety risk) of transportation and operation facilities based on the infectious characteristics of medical waste.

In terms of the medical waste reverse logistics network under the COVID-19 epidemic, Tirkolaee et al. (2021) hypothesized that time windows play a key role in prioritizing hospital services in different risk ranges. They developed a mixed-integer linear programming model with the objectives of minimum transport time, minimum total number of people violating the time windows, and minimum number of people in waste disposal facilities. Liu et al. (2020b) developed a twostage model considering environmental, traffic, and vehicle load factors for the problem of selecting temporary storage centers for medical waste and actual transportation flow. Kargar et al. (2020b) considered all sites where medical waste may be generated in Babol city and developed a model with the objectives of minimizing cost, risk of transportation and disposal facilities, and amount of uncollected waste. Yu et al. (2020) constructed a multi-period mixed-integer programming model with the objectives of minimizing cost, risk at source, and risk at transportation and operation facilities using the Wuhan City COVID-19 epidemic as a study. The results showed that the installation of temporary incinerators and other equipment could effectively handle the surge of medical waste.

From a review of the aforementioned literature, it can be concluded that the reverse logistics network optimization generally adopts a mixed-integer programming model; current network optimization models often adopt the multi-objective multi-period mixed-integer programming model. Over the years, these models have gradually started considering the economic, environmental, and social benefits to achieve the 
effective unification of social, environmental, and economic benefits (Hao et al. 2020). Owing to the outbreak of SARS, COVID-19, and other public health emergencies, the research direction has gradually turned to medical waste, but there is less research on the construction of medical waste networks under the COVID-19 epidemic. Additionally, there is almost no network that considers the actual situation of commandeering existing domestic waste incineration centers and hazardous waste incineration centers as synergistic disposal facilities.

In this study, with the objectives of minimizing cost, safety risk, and time, we consider the cost of disinfection of medical waste reverse logistics recycling and closure and requisitioning synergistic facilities such as domestic waste incineration centers and hazardous waste incineration centers. The construction cost of new temporary medical waste disposal centers, the probability of accidental risk during transportation, the probability of accidental risk at each facility, the population of exposures, time urgency, and other various factors are also considered. A multi-objective multi-period mixed-integer nonlinear programming model is constructed considering the bottlenecks of disposal capacity to determine the location of each facility and the amount of medical waste allocated to each facility. A case study of medical waste disposal in New York City, USA, is also presented.

\section{Model}

\section{Problem definition}

The objective of this study is to design a medical waste recycling network that resolves the bottlenecks of disposal capacity during the COVID-19 epidemic. The main infrastructures of this network are hospitals, sterilization transfer centers, existing medical waste disposal centers, domestic waste incineration centers (requisitioned), hazardous waste incineration centers (requisitioned), newly constructed temporary medical waste disposal centers, and harmless disposal centers as shown in Figure 1. The hospital sends the medical waste generated under the COVID-19 epidemic to the hospital's storage room for temporary storage after specialized treatment. The waste will then be transported by special vehicles to the medical waste disposal center for corresponding treatment. At the beginning of the COVID-19 epidemic, all medical waste were sent to existing medical waste disposal centers for treatment because of the small amount of medical waste. When the amount of medical waste generated increased dramatically, priority was given to the requisition of emergency co-disposal facilities such as domestic waste incineration centers and hazardous waste incineration centers (Yang et al. 2021), after which a newly constructed temporary medical waste disposal center was considered.

\section{Model assumptions}

The assumptions made while designing this model are as follows:

(1) All waste generated by the hospital was transported to the sterilization transfer center.

(2) Because the risk of the waste residues after treatment at the disposal centers or incineration centers is minimized and can be safely stored, transported, and disposed, the risk of storage, transportation, and disposal to the harmless treatment centers is not taken into account in the mixed-integer nonlinear programming model.

(3) In the case of an emergency, medical waste can be transported to the domestic waste incineration center for treatment; its treatment volume will not exceed $5 \%$ of the disposal capacity of the domestic waste incineration center. The maximum disposal capacity of medical waste in a hazardous waste incineration center is determined according to the spare capacity that can be deployed in the facility.

(4) The medical waste recycling treatment regarded in this study mainly considers medical waste generated by medical institutions; it does not consider hospital waste isolated at home.

\section{Model building}

\section{Facility points}

$i$-set of hospitals $i \in\{1,2 \ldots . . I\}$

$j$-set of sterilization transfer centers $j \in\{1,2 \ldots . J\}$

$d$-set of domestic waste incineration centers (requisitioned) $d \in\{1,2 \ldots . D\}$

$h$-set of hazardous waste incineration centers (requisitioned) $h \in\{1,2 \ldots . . H\}$

$t$ - set of newly constructed temporary medical waste disposal centers $t \in\{1,2 \ldots . T\}$

$e$ - set of existing medical waste disposal centers $e \in\{1$, $2 \ldots . E$;

$l$-set of harmless disposal centers $l \in\{1,2 \ldots . L\}$

$p$-set of periods $p \in\{1,2 \ldots . P\}$

\section{Model parameters}

$F C_{j}^{p}$ — fixed cost of establishing sterilization transfer centers $j$ during period $p$

$F C_{d}^{p}$ - fixed cost of domestic waste incineration centers $d$ requisitioned during period $p$ 


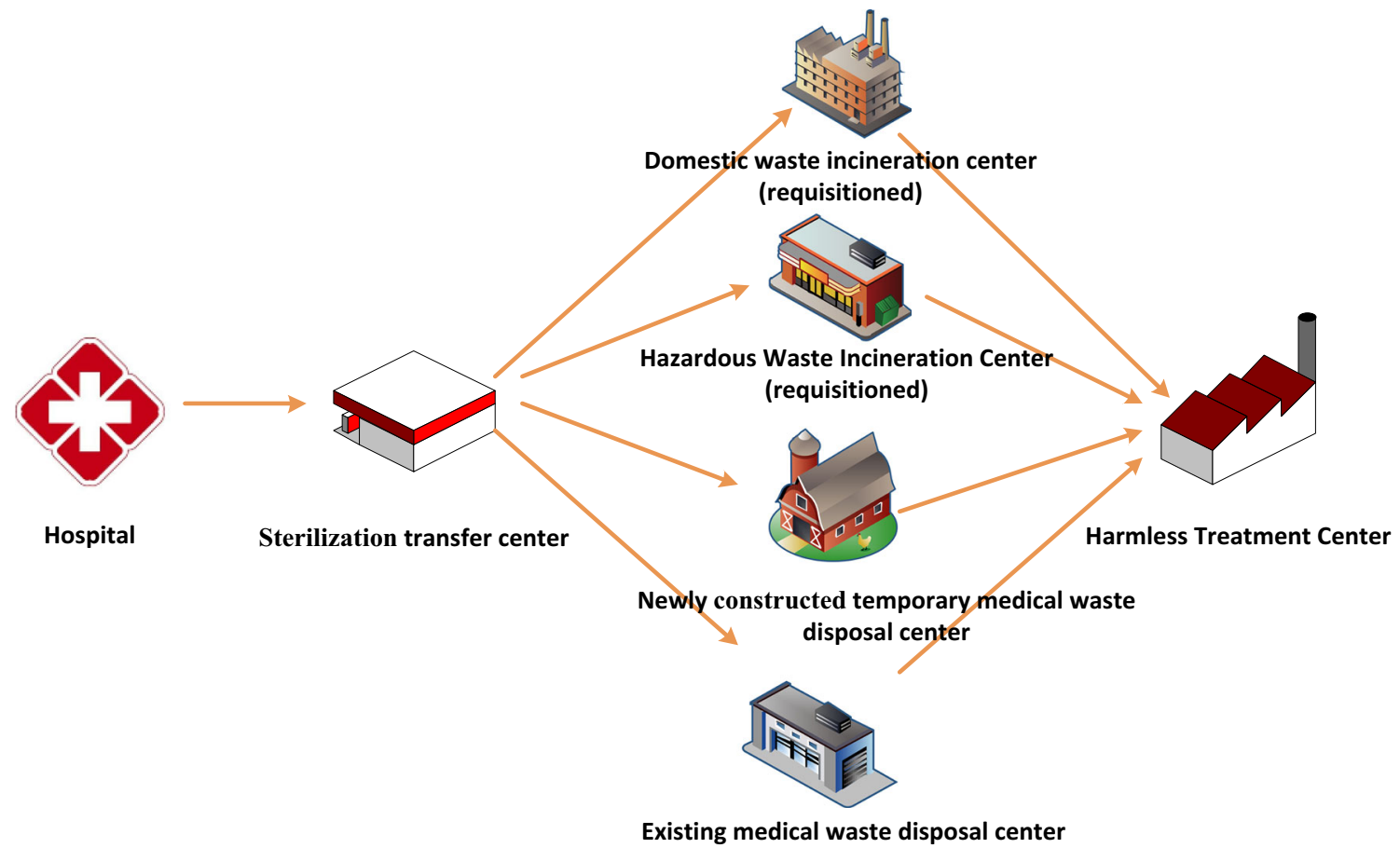

Fig. 1 Medical waste reverse logistics recycling and treatment network under the COVID-19 epidemic

$F C_{h}^{p}$ - fixed cost of hazardous waste incineration centers $h$ requisitioned during period $p$

$F C_{t}^{p}$ - fixed costs of newly constructed temporary medical waste disposal centers $t$ during period $p$

$f c_{j}^{p}$ - fixed costs of closure of sterilization transfer centers $j$ in period $p$

$f c_{t}^{p}$ - fixed costs of closure of newly constructed temporary medical waste disposal centers $t$ during period $p$

$O C_{j}^{p}$ - operating costs of sterilization transfer centers $j$ during period $p$

$O C_{d}^{p}$ —operating costs of domestic waste incineration centers (requisitioned) $d$ during period $p$

$O C_{h}^{p}$ —operating costs of hazardous waste incineration centers (requisitioned) $h$ during period $p$

$O C_{t}^{p}$ —operating costs of newly constructed temporary medical waste disposal centers $t$ during period $p$

$O C_{e}^{p}$-operating cost of existing medical waste disposal centers $e$ during period $p$

$T C_{j}^{p}$ —unit disposal cost of sterilization transfer centers $j$ during period $p$

$T C_{d}^{p}$ —unit disposal cost of domestic waste incineration centers (requisitioned) $d$ during period $p$

$T C_{h}^{p}$ — unit disposal cost of hazardous waste incineration centers (requisitioned) $h$ during period $p$

$T C_{t}^{p}$ — unit disposal cost of newly constructed temporary medical waste disposal centers $t$ during period $p$

$T C_{e}^{p}$ —unit disposal cost of existing medical waste disposal centers $e$ during period $p$
$D C_{j}^{p}$ —disinfection cost of sterilization transfer centers $j$ during period $p$

$C A_{j}^{p}$-maximum processing capacity of sterilization transfer centers $j$ during period $p$

$C A_{d}^{p}$ - maximum processing capacity of domestic waste incineration centers (requisitioned) $d$ during period $p$

$C A_{h}^{p}$-maximum processing capacity of hazardous waste incineration centers (requisitioned) $h$ during period $p$

$C A_{t}^{p}$-maximum processing capacity of newly constructed temporary medical waste disposal centers $t$ during period $p$

$C A_{e}^{p}$-maximum processing capacity of existing medical waste disposal centers $e$ during period $p$

$T D_{i j}$ distance from hospital $i$ to sterilization transfer center $j$

$T D_{j d}$-distance from the sterilization transfer center $j$ to the domestic waste incineration center (requisitioned) $d$

$T D_{j h}$-distance from the sterilization transfer center $j$ to hazardous waste incineration center (requisitioned) $h$

$T D_{j t}$-distance from the sterilization transfer center $j$ to newly constructed temporary medical waste disposal center $t$

$T D_{j e}$-distance from the sterilization transfer center $j$ to existing medical waste disposal center $e$

$C C_{i j}$ unit transportation cost from hospital $i$ to sterilization transfer center $j$

$C C_{j d}$ - unit transportation cost from sterilization transfer center $j$ to domestic waste incineration center (requisitioned) $d$

$C C_{j h}$ - unit transportation cost from sterilization transfer center $j$ to hazardous waste incineration center (requisitioned) $h$ 
$C C_{j t}$ - unit transportation cost from sterilization transfer center $j$ to newly constructed temporary medical waste disposal center $t$

$C C_{j e}$ - unit transportation cost from sterilization transfer center $j$ to existing medical waste disposal center $e$

$M P_{j}$ _maximum number of sterilization transfer centers $j$ constructed

$M P_{d}$-maximum number of domestic waste incineration centers (requisitioned) $d$

$M P_{h}$ - maximum number of hazardous waste incineration centers (requisitioned) $h$

$M P_{t}$-maximum number of newly constructed temporary medical waste disposal centers $t$

$A R_{j}$ - probability of accidental risk in sterilization transfer center $j$

$A R_{d}$-probability of accidental risk in domestic waste incineration center (requisitioned) $d$

$A R_{h}$ - probability of accidental risk in hazardous waste incineration center (requisitioned) $h$

$A R_{t}$ - probability of accidental risk in newly constructed temporary medical waste disposal center $t$

$A R_{e}$ - probability of accidental risk in existing medical waste disposal center $e$

$W R_{i j}$ - probability of accidental risk during transportation from hospital $i$ to sterilization transfer center $j$

$W R_{j d}$-probability of accidental risk during transportation from sterilization transfer center $j$ to domestic waste incineration center (requisitioned) $d$

$W R_{j h}$ - probability of accidental risk during transportation from sterilization transfer center $j$ to hazardous waste incineration center (requisitioned) $h$

$W R_{j t}$-probability of accidental risk during transportation from sterilization transfer center $j$ to newly constructed temporary medical waste disposal center $t$

$W R_{j e}$-probability of accidental risk during transportation from sterilization transfer center $j$ to existing medical waste disposal center $e$

$P P_{j}$-number of sterilization transfer centers $j$ population exposed

$P P_{d}$-number of domestic waste incineration centers (requisitioned) $d$ population exposed

$P P_{h}$-number of hazardous waste incineration centers (requisitioned) $h$ population exposed

$P P_{t}$-number of newly constructed temporary medical waste disposal centers $t$ population exposed

$P_{e}$ - number of existing medical waste disposal centers $e$ population exposed

$W P_{i j}$-population exposure in transit from hospitali to sterilization transfer center $j$

$W P_{j d}$-population exposure in transit from the sterilization transfer center $j$ to domestic waste incineration center (requisitioned) $d$
$W P_{j h}$-population exposure in transit from sterilization transfer center $j$ to hazardous waste incineration center (requisitioned) $h$

$W P_{j t}$-population exposure in transit from the sterilization transfer center $j$ to the newly constructed temporary medical waste disposal center $t$

$W P_{j e}$-population exposure in transit from sterilization transfer center $j$ to existing medical waste disposal center $e$

$C Q_{i}^{p}$ - amount of medical waste generated by hospital $i$ during period $p$

$P T_{i}^{p}$ —number of patients accepted by hospital $i$ during period $p$

$q$-amount of medical waste generated per capita in hospital $i$

\section{Objective functions}

Here, the construction of a medical waste recycling network model is presented considering disposal capacity bottlenecks under the COVID-19 epidemic with the objectives of minimizing cost, safety risk, and time.

$$
\begin{aligned}
& \min F=C+Z+W \\
& C=C_{1}+C_{2}+C_{3}+C_{4}+C_{5}+C_{6} \\
& Z=Z_{1}+Z_{2} \\
& W=\sum_{p \in P} \sum_{i \in I} \sum_{j \in J} X_{j}^{p} T D_{i j}+\sum_{p \in P} \sum_{j \in J} \sum_{d \in D} X_{d}^{p} \cdot T D_{j d}+ \\
& \sum_{p \in P} \sum_{j \in J} \sum_{h \in H} X_{h}^{p} \cdot T D_{j h}+\sum_{p \in P} \sum_{j \in J} \sum_{t \in T} X_{t}^{p} \cdot T D_{j t} \\
& \quad+\sum_{p \in P} \sum_{j \in J} \sum_{e \in E} T D_{j e} \cdot X_{e}^{p}
\end{aligned}
$$

$$
\begin{aligned}
C_{1} & =\sum_{j \in J} \sum_{p \in P} F C_{j}^{p} \cdot\left(\frac{X_{j}^{p}-X_{j}^{p-1}+1}{2}\right) \\
& +\sum_{d \in D} \sum_{p \in P} F C_{d}^{p} \cdot\left(\frac{X_{d}^{p}-X_{d}^{p-1}+1}{2}\right) \\
& +\sum_{h \in H} \sum_{p \in P} F C_{h}^{p} \cdot\left(\frac{X_{h}^{p}-X_{h}^{p-1}+1}{2}\right) \\
& +\sum_{t \in T} \sum_{p \in P} F C_{t}^{p} \cdot\left(\frac{X_{t}^{p}-X_{t}^{p-1}+1}{2}\right) \\
C_{2}= & \sum_{j \in J} \sum_{p \in P} f c_{j}^{p} \cdot\left|\left(\frac{X_{j}^{p}-X_{j}^{p-1}-1}{2}\right)\right| \\
& +\sum_{t \in T} \sum_{p \in P} f c_{t}^{p} \cdot\left|\left(\frac{X_{t}^{p}-X_{t}^{p-1}-1}{2}\right)\right|
\end{aligned}
$$


$C_{3}=\sum_{j \in J} \sum_{p \in P} O C_{j}^{p} X_{j}^{p}+\sum_{j \in J} \sum_{p \in P} T C_{j}^{p} H Q_{j}^{p}+\sum_{d \in D} \sum_{p \in P} O C_{d}^{p} X_{d}^{p}+$ $\sum_{d \in \mathrm{D}} \sum_{p \in P} T C_{d}^{p} H Q_{d}^{p}+\sum_{h \in H} \sum_{p \in P} O C_{h}^{p} X_{h}^{p}+\sum_{h \in H} \sum_{p \in P} T C_{h}^{p} H Q_{h}^{p}+$ $\sum_{t \in T} \sum_{p \in P} O C_{t}^{p} X_{t}^{p}+\sum_{t \in T} \sum_{p \in P} T C_{t}^{p} H Q_{t}^{p}+\sum_{e \in E} \sum_{p \in P} O C_{e}^{p} X_{e}^{p}+$ $\sum_{e \in E} \sum_{p \in P} T C_{e}^{p} H Q_{e}^{p}$

$$
\begin{aligned}
C_{4} & =\sum_{i \in I} \sum_{j \in J} \sum_{p \in P} D C_{j}^{p} T Q_{i j}^{p} \\
C_{5}= & \sum_{i \in I} \sum_{j \in J} \sum_{p \in P} T D_{i j} T Q_{i j}^{p} C C_{i j}^{p}+\sum_{j \in J} \sum_{d \in D} \sum_{p \in P} T D_{j d} T Q_{j d}^{p} C C_{j d}^{p} \\
& +\sum_{j \in J} \sum_{h \in H} \sum_{p \in P} T D_{j h} T Q_{j h}^{p} C C_{j h}^{p}+\sum_{j \in J} \sum_{t \in T} \sum_{p \in P} T D_{j t} T Q_{j t}^{p} C C_{j t}^{p} \\
& +\sum_{j \in J} \sum_{e \in E} \sum_{p \in P} T D_{j e} T Q_{j e}^{p} C C_{j e}^{p} \\
Z_{1}= & \sum_{i \in I} \sum_{j \in J} \sum_{p \in P} W R_{i j} W P_{i j} T Q_{i j}^{p}+\sum_{j \in J} \sum_{d \in D} \sum_{p \in P} W R_{j d} W P_{j d} T Q_{j d}^{p} \\
& +\sum_{j \in J} \sum_{h \in H} \sum_{p \in P} W R_{j h} W P_{j h} T Q_{j h}^{p}+\sum_{j \in J} \sum_{t \in T} \sum_{p \in P} W R_{j t} W P_{j t} T Q_{j t}^{p} \\
& +\sum_{j \in J} \sum_{e \in E} \sum_{p \in P} W R_{j e} W P_{j e} T Q_{j e}^{p} \\
Z_{2}= & \sum_{j \in J} \sum_{p \in P} A R_{j} P P_{j} H Q_{j}^{p}+\sum_{d \in D} \sum_{p \in P} A R_{d} P P_{d} H Q_{d}^{p} \\
& +\sum_{h \in H} \sum_{p \in P} A R_{h} P P_{h} H Q_{h}^{p}+\sum_{t \in T} \sum_{p \in P} A R_{t} P P_{t} H Q_{t}^{p} \\
& +\sum_{e \in E} \sum_{p \in P} A R_{e} P P_{e} H Q_{e}^{p}
\end{aligned}
$$

Objective function (1) represents the overall objective of this study, which is to achieve the minimum cost, safety risk, and time. Objective function (2) represents the minimum cost of medical waste in each period. Equation (5) represents the sum of the fixed costs of construction and requisition of facility sites in each period. Here, $\sum_{j \in J} \sum_{p \in P} F C_{j}^{p} \cdot\left(\frac{X_{j}^{p}-X_{j}^{p-1}+1}{2}\right)$ represents the fixed costs of the sterilization transfer centers, $\sum_{d \in D} \sum_{p \in P} F C_{d}^{p} \cdot\left(\frac{X_{d}^{p}-X_{d}^{p-1}+1}{2}\right)$ represents the fixed costs of the domestic waste incineration centers (requisitioned), $\sum_{h \in H} \sum_{p \in P}$ $F C_{h}^{p} \cdot\left(\frac{X_{h}^{p}-X_{h}^{p-1}+1}{2}\right)$ represents the fixed costs of the hazardous waste incineration centers (requisitioned), and $\sum_{t \in T} \sum_{p \in P} F C_{t}^{p}$. $\left(\frac{X_{t}^{p}-X_{t}^{p-1}+1}{2}\right)$ represents the fixed cost of the newly constructed temporary medical waste disposal centers $t$.

Equation (6) represents the sum of the fixed costs of closing the facility sites in each period, where $\sum_{j \in J} \sum_{p \in P} f c_{j}^{p}$. $\left(\frac{X_{j}^{p}-X_{j}^{p-1}-1}{2}\right) \mid$ represents the closing costs of the sterilization transfer centers and $\sum_{t \in T} \sum_{p \in P} f c_{t}^{p} \cdot\left|\left(\frac{X_{t}^{p}-X_{t}^{p-1}-1}{2}\right)\right|$ represents the closing costs of newly constructed temporary medical waste disposal centers.

Equation (7) represents the sum of operating and disposal costs for each period. Here, $\sum_{j \in J} \sum_{p \in P} O C_{j}^{p} X_{j}^{p}$ represents the operating costs of the sterilization transfer centers, $\sum_{j \in J} \sum_{p \in P}$
$T C_{j}^{p} H Q_{j}^{p}$ represents the disposal costs of the sterilization transfer centers, $\sum_{d \in D} \sum_{p \in P} O C_{d}^{p} X_{d}^{p}$ represents the operating costs of the domestic waste incineration centers (requisitioned), $\sum_{d \in D}$ $\sum_{p \in P} T C_{d}^{p} H Q_{d}^{p}$ represents the disposal costs of the domestic waste incineration centers (requisitioned), $\sum_{h \in H} \sum_{p \in P} O C_{h}^{p} X_{h}^{p}$ represents the operating costs of the hazardous waste incineration centers (requisitioned), $\sum_{h \in H} \sum_{p \in P} T C_{h}^{p} H Q_{h}^{p}$ represents the disposal costs of the hazardous waste incineration centers (requisitioned), $\sum_{t \in T} \sum_{p \in P} O C_{t}^{p} X_{t}^{p}$ represents the operating costs of the newly constructed temporary medical waste disposal center, $\sum_{t \in T} \sum_{p \in P} T C_{t}^{p} H Q_{t}^{p}$ represents the disposal costs of the newly constructed temporary medical waste disposal center, $\sum_{e \in E} \sum_{p \in P} O C_{e}^{p} X_{e}^{p}$ represents the operating costs of the existing medical waste disposal centers, and $\sum_{e \in E} \sum_{p \in P} T C_{e}^{p}$ $H Q_{e}^{p}$ represents the disposal cost of the existing medical waste disposal centers.

Equation (8) represents the disinfection costs of the sterilization transfer centers. Equation (9) represents the sum of transportation costs in each period, wherein $\sum_{i \in I} \sum_{j \in J} \sum_{p \in P}$ $T D_{i j} T Q_{i j}^{p} C C_{i j}^{p}$ represents the transportation costs from hospitals to the sterilization transfer centers, $\sum_{j \in J} \sum_{d \in D} \sum_{p \in P} T D_{j d}$ $T Q_{j d}^{p} C C_{j d}^{p}$ represents the transportation costs from the sterilization transfer centers to the domestic waste incineration centers (requisitioned), $\sum_{j \in J} \sum_{h \in H} \sum_{p \in P} T D_{j h} T Q_{j h}^{p} C C_{j h}^{p}$ represents the transportation costs from the sterilization transfer centers to the hazardous waste incineration centers (requisitioned), $\sum_{j \in J} \sum_{t \in T} \sum_{p \in P} T D_{j t} T Q_{j t}^{p} C C_{j t}^{p}$ represents the transportation costs from the sterilization transfer centers to the newly constructed temporary medical waste disposal centers, and $\sum_{j \in J}$ $\sum_{e \in E} \sum_{p \in P} T D_{j e} T Q_{j e}^{p} C C_{j e}^{p}$ represents the transportation costs from the sterilization transfer centers to the existing medical waste disposal.

Objective function (3) represents the minimal risk of medical waste in each period. Equation (10) represents the sum of the risks during transportation in each period, wherein $\sum_{i \in I}$ $\sum_{j \in J} \sum_{p \in P} W R_{i j} W P_{i j} T Q_{i j}^{p}$ represents the transportation risks from hospitals to the sterilization transfer centers, $\sum_{j \in J} \sum_{d \in D}$ $\sum_{p \in P} W R_{j d} W P_{j d} T Q_{j d}^{p}$ represents the transportation risks from the sterilization transfer centers to the domestic waste incineration centers (requisitioned), $\sum_{j \in J} \sum_{h \in H} \sum_{p \in P} W R_{j h} W P_{j h} T Q_{j h}^{p}$ represents the transportation risks from the sterilization transfer centers to the hazardous waste incineration centers (requisitioned), $\sum_{j \in J} \sum_{t \in T} \sum_{p \in P} W R_{j t} W P_{j t} T Q_{j t}^{p}$ represents the transportation risks from the sterilization transfer centers to the newly constructed temporary medical waste disposal centers, and $\sum_{j \in J} \sum_{e \in E} \sum_{p \in P} W R_{j e} W P_{j e} T Q_{j e}^{p}$ represents the transportation risks from the sterilization transfer centers to the existing medical waste disposal centers. 
Equation (11) represents the sum of the risks of each facility in each period, wherein $\sum_{j \in J} \sum_{p \in P} A R_{j} P P_{j} H Q_{j}^{p}$ represents the possible risks of the sterilization transfer centers, $\sum_{d \in D}$ $\sum_{p \in P} A R_{d} P P_{d} H Q_{d}^{p}$ represents the possible risks of the domestic waste incineration center (requisitioned), $\sum_{h \in H} \sum_{p \in P} A R_{h}$ $P P_{h} H Q_{h}^{p}$ represents the possible risks of the hazardous waste incineration center (requisitioned), $\sum_{t \in T} \sum_{p \in P} A R_{\mathrm{t}} P P_{t} H Q_{t}^{p}$ represents the possible risks of the newly constructed temporary medical waste disposal centers, and $\sum_{e \in E} \sum_{p \in P} A R_{e} P P_{e} H Q_{e}^{p}$ represents the possible risks of the existing medical waste disposal centers.

Objective function (4) requires that medical waste be recycled and disposed of in the shortest possible time to reduce the environmental impact.

\section{Constraints}

$$
\begin{aligned}
& \sum_{j \in J} T Q_{i j}^{p} X_{j}^{p}=C Q_{i}^{p}, \forall i, p \\
& \sum_{i \in I} T Q_{i j}^{p} X_{j}^{p}=H Q_{j}^{p} X_{j}^{p}, \forall j, p \sum_{i \in I} T Q_{i j}^{p} X_{j}^{p}=\sum_{d \in D} T Q_{j d}^{p} X_{d}^{p}+\sum_{h \in H} T Q_{j h}^{p} X_{h}^{p} \\
&+\sum_{t \in T} T Q_{j t}^{p} X_{t}^{p} \sum_{e \in E} T Q_{j e}^{p} X_{e}^{p}, \forall j, p \\
& \sum_{d \in D} T Q_{j d}^{p} X_{d}^{p}=H Q_{d}^{p} X_{d}^{p}, \forall d \in D, p \in P \\
& \sum_{h \in H} T Q_{j h}^{p} X_{h}^{p}=H Q_{h}^{p} X_{h}^{p}, \forall h \in H, p \in P \\
& \sum_{t \in T} T Q_{j t}^{p} X_{t}^{p}=H Q_{t}^{p} X_{t}^{p}, \forall t \in T, p \in P \\
& \sum_{e \in E} T Q_{j e}^{p} X_{e}^{p}=H Q_{e}^{p}, \forall e \in E, p \in P \\
& \sum_{i \in I} T Q_{i j}^{p} X_{j}^{p} \leq C A_{j}^{p}, \forall j \in J, p \in P \\
& \sum_{d \in D} T Q_{j d}^{p} X_{d}^{p} \leq C A_{d}^{p}, \forall d \in D, p \in P \\
& \sum_{h \in H} T Q_{j h}^{p} X_{h}^{p} \leq C A_{h}^{p}, \forall h \in H, p \in P \\
& \sum_{t \in T} T Q_{j t}^{p} X_{t}^{p} \leq C A_{t}^{p}, \forall t \in T, p \in P \\
& \sum_{e \in E} T Q_{j e}^{p} X_{e}^{p} \leq C A_{e}^{p}, \forall e \in E, p \in P \\
& 1 \leq \sum_{j \in J} X_{j}^{p} \leq M P_{j}, \forall p \\
& 1 \leq \sum_{d \in D} X_{d}^{p} \leq M P_{d}, \forall p \\
& 1 \leq \sum_{h \in H} X_{h}^{p} \leq M P_{h}, \forall p \\
& 1 \leq \sum_{t \in T} X_{t}^{p} \leq M P_{t}, \forall p \\
& 1 \leq \sum_{e \in E} X_{e}^{p} \leq M P_{e}, \forall p \\
& X_{j}^{p}, X_{d}^{p}, X_{t}^{p}, X_{h}^{p}, X_{e}^{p} \in\{0,1\}, \forall j \in J, d \in D, t \in T, h \in H, e \in E, p \in P \\
&
\end{aligned}
$$

$$
\begin{aligned}
& C Q_{i}^{p}, H Q_{j}^{p}, H Q_{d}^{p}, H Q_{t}^{p}, H Q_{h}^{p}, H Q_{e}^{p} \geq 0, \forall i \in I, j \in J, d \in D, \\
& \quad t \in T, h \in H, e \in E, p \in P
\end{aligned}
$$

$$
T Q_{i j}^{p}, T Q_{j d}^{p}, T Q_{j h}^{p}, T Q_{j t}^{p}, T Q_{j e}^{p} \geq 0, \forall i \in I, j \in J, d \in D, t \in T,
$$
$h \in H, e \in E, p \in P$

The constraint variable (12) indicates that the amount transported from the hospitals to the sterilization transfer centers is equal to the amount of medical waste generated by the hospitals, where $G Q_{i}^{p}$ is an epidemic-affected variable that varies with time, $G Q_{i}^{p}=\sum_{i \in I} \sum_{p \in P} P T_{i}^{p} \cdot q$ (Yu et al. 2020). The constraint variable (13) indicates that the amount of medical waste transported from the hospitals to the sterilization transfer centers is equal to the amount of medical waste transported to the sterilization transfer centers. The constraint variable (14) indicates that the amount of medical waste in the sterilization transfer center is equal to the sum of the amount of medical waste transported from the sterilization transfer centers to the domestic waste incineration centers (requisitioned) and the hazardous waste incineration centers (requisitioned), that transported to the newly constructed temporary medical waste disposal centers, and that transported to the existing medical waste disposal centers. The constraint variable (15) indicates that the amount of medical waste transported from the sterilization transfer centers to the domestic waste incineration centers (requisitioned) is equal to the amount of medical waste in the domestic waste incineration centers (requisition). The constraint variable (16) indicates that the amount of medical waste transported from the sterilization transfer centers to the hazardous waste incineration centers (requisitioned) is equal to the amount of medical waste in the hazardous waste incineration centers (requisitioned). The constraint variable (17) indicates that the amount of medical waste transported from the sterilization transfer centers to the newly constructed temporary medical waste disposal centers is equal to the amount of medical waste in the newly constructed temporary medical waste disposal centers. The constraint variable (18) indicates that the amount of medical waste transported from the sterilization transfer centers to the existing medical waste disposal centers is equal to the amount of medical waste in the existing medical waste disposal centers. The constraint variables (1923 ) indicate that the amount of medical waste in the respective centers does not exceed their maximum processing capacity. The constraint variable (24) indicates that the number of sterilization transfer centers does not exceed the maximum number of constructed centers. The constraint variable (25) indicates that the number of requisitioned domestic waste incineration centers does not exceed the maximum number required. The constraint variable (26) indicates that the number of requisitioned hazardous waste incineration centers does not exceed the maximum number required. The constraint variable (27) 
indicates that the number of newly constructed temporary medical waste disposal centers does not exceed the maximum number of constructed centers. The constraint variable (28) indicates that the number of existing medical waste disposal centers used does not exceed the maximum available number. The constraint variable (29) indicates that all the decision variables are $0-1$ variables. Constraint variables (30) and (31) indicate the nonnegativity of the variables.

\section{Empirical analysis}

In this section, numerical experimental results of this mixedinteger nonlinear programming model are presented. First, an example of medical waste recycling in New York City hospitals in the USA under the COVID-19 epidemic is presented, followed by the computational results and a case study.

\section{Case study}

This study constructs a medical waste recycling network considering disposal capacity bottlenecks, using medical waste recycling in hospitals in New York City, USA, as an example. The facility nodes include hospitals, sterilization transfer centers, existing medical waste disposal centers, domestic waste incineration centers (requisitioned), hazardous waste incineration centers (requisitioned), newly constructed temporary medical waste disposal centers, and harmless disposal centers. Based on the predicted number of COVID-19 patients in the next 3 months and $G Q_{i}^{p}=\sum_{i \in I} \sum_{p \in P} P T_{i}^{p} \cdot q$ (Yu et al. 2020), the siting and flow allocation of the aforementioned centers in the medical waste recycling network in New York City, USA, were studied.

New York City, USA, has experienced an exponential growth in the number of COVID-19 patients since the outbreak in the country on March 3,2020, and the situation is critical (Zhang et al. 2020). In this study, a third-order polynomial function was fitted to predict the cumulative daily number of patients with COVID-19 in New York City, USA, from March 3, 2020, to March 3, 2021, as published by the NYC Health (Health 2021). Various algorithms have been used for prediction; for example, Hao et al. (2018b) used a hybrid model based on an artificial neural network and a gray model to predict the number of end-of-life vehicles. Hao et al. (2019) predicted the amount of medical waste based on a hybrid neural network with gray model (GM), triple exponential smoothing (TES), and particle swarm optimization (PSO). The polynomial function is also a very important statistical analysis method for establishing a relationship between one or more independent variables and dependent variables to predict the change in data over time when the data have certain patterns within them. Polynomial fitting solves a function similar to $p_{n}=\sum_{k=0}^{n} a_{k} x^{k} \in \varnothing$ (Huang and Liu 2021). Currently, polynomial prediction models have been used to predict the trend of the COVID-19 epidemic with good applicability (Amar et al. 2020; Orihuel et al. 2021); thus, a thirdorder polynomial function model was used to predict the trend of the COVID-19 epidemic in New York City, USA, as the number of infections in the city continues to show exponential growth (Fig. 2) (Akhtar 2020).

The model was used to fit and combine the forecasts, and a functional relationship was obtained, as shown in (32). The number of COVID-19 patients predicted from March 4, 2021, to June 4, 2021, is shown in Table 2. There were three periods of approximately 30 days each.

$f(x)=p_{1} \times x^{3}+p_{2} \times x^{2}+p_{3} \times x+p_{4}$

where the correlation coefficients are as follows.

$p_{1}=0.0679 \quad p_{2}=-33.08 \quad p_{3}=5543 \quad p_{4}=-47410$

As tested using Matlab 2019a, the R-square of the polynomial function tends to 1 at a confidence interval of $95 \%$, as shown in Table 1, indicating that the third-order polynomial function is a good fit.

Therefore, based on this functional equation (31), the number of patients with COVID-19 in New York City, USA, from March 4, 2021, to June 4, 2021, was calculated as shown in Table 2.

The daily generation of medical waste per bed in the USA is $2.5 \mathrm{~kg}$ (Janagi et al. 2015). However, during the COVID-19 epidemic, the increase in demand for medical supplies such as masks, gowns, and goggles, as well as the fact that the domestic waste generated per patient bed is also highly infectious, led to a dramatic increase in medical waste. Therefore, this study assumed that the amount of medical waste generated per bed per day is $5 \mathrm{~kg}$.

According to the list of hospitals provided by NYS Health Profiles (Profiles 2021), there are currently 35 hospitals in New York City that accept COVID-19 patients. The names, locations, and current capacities of the hospitals are listed in Table 3.

The number of hospitals receiving COVID-19 patients was estimated based on the proportion of hospital beds (Wang et al. 2019b; Yu et al. 2020). The amount of hospital waste generated per period was calculated based on the predicted results as well as $G Q_{i}^{p}=\sum_{i \in I} \sum_{p \in P} P T_{i}^{p} \cdot q$ (Yu et al. 2020); the values for each hospital are shown in Table 4. Owing to the dramatic increase in the number of patients during COVID-19, the existing capacity of the hospital could not meet the demand of everyone for the time being. Hence, it was assumed that patients with mild symptoms were isolated 
Fig. 2 Third-order polynomial function prediction

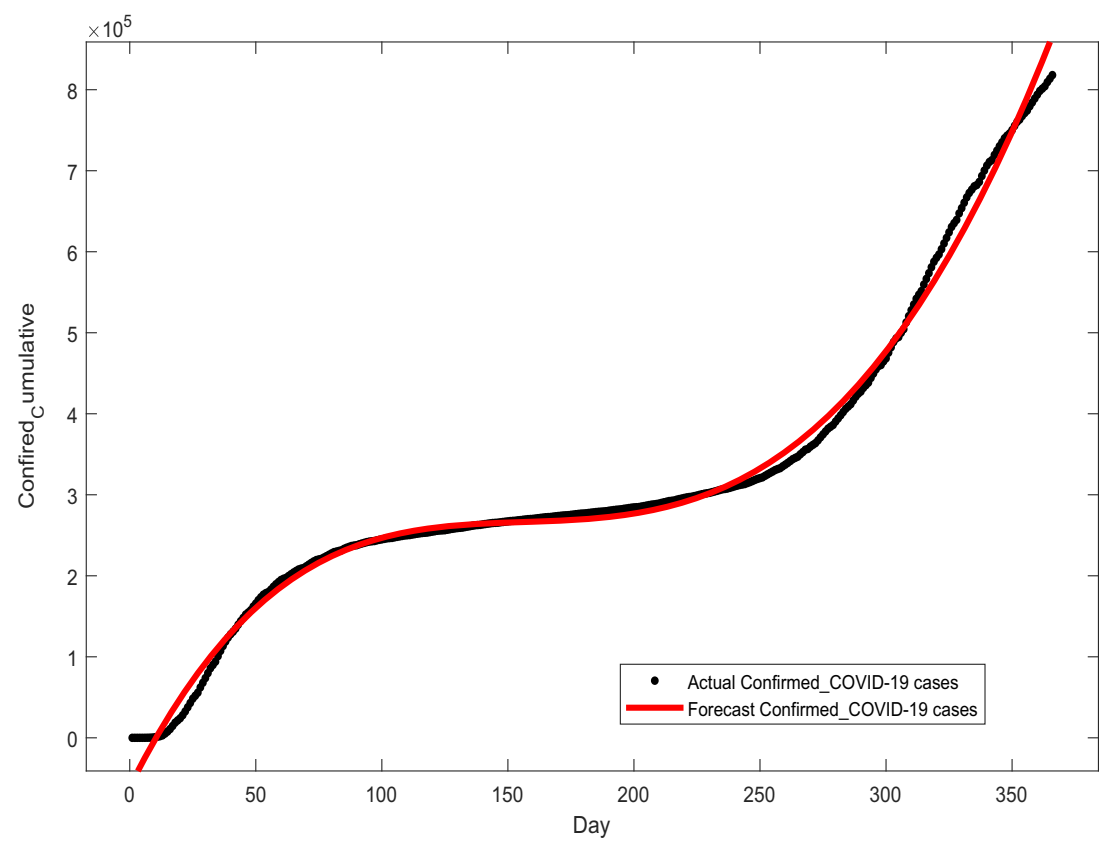

at home and their generated medical waste was collected and sent to the nearby hospital staging room by specialized volunteers for temporary storage and subsequent unified disposal.

The volume of medical waste is growing exponentially and rapidly, and the storage capacity of hospital staging rooms cannot meet this demand. Therefore, this study considers the establishment of sterilization transfer centers in waste transfer centers in New York City for temporary storage of medical waste; the names and locations of the alternative sites are shown in Table 5. There are currently nine medical waste disposal centers in New York City, and it is assumed that their disposal capacity is about 12,000 tons per year, of which $60 \%$ is used to treat highly infectious medical waste under COVID19; the specific names and locations are shown in Table 6. Moreover, existing domestic waste incineration centers, hazardous waste incineration centers, and other synergistic facilities were requisitioned; the names and locations of the alternative sites of domestic waste incineration (requisitioned) and hazardous waste incineration (requisitioned) centers are shown in Tables 7 and 8. It is assumed that the domestic waste incineration centers dispose of 43,200 tons of domestic waste per year; $5 \%$ of the capacity is used to dispose of medical waste under the COVID-19 epidemic (Environment 2019). Moreover, hazardous waste incineration centers are assumed

Table 1 Description of the third-order polynomial function fit

\begin{tabular}{ll}
\hline Parameters & Description \\
\hline SSE & 75900000000 \\
R-square & 0.9942 \\
Adjusted R-square & 0.9941 \\
RMSE & 14480 \\
\hline
\end{tabular}

to have an annual disposal capacity of 28,320 tons, of which $10 \%$ of the capacity is used to dispose of medical waste under the COVID-19 epidemic (Environment 2010). This study also considered the establishment of temporary medical waste disposal centers in the vicinity of two existing hospitals to dispose of medical waste; the names of the alternative sites and their latitude and longitude are shown in Table 9.

The transportation distance between each facility point in this study is the Euclidean distance. The cost of transporting medical waste was 35 yuan $/$ ton $/ \mathrm{km}$. The possible risks during transport were quantified using the arithmetic formula of transport risk $=0.36 \times$ travel length $\times 10^{-6}(\mathrm{Yu}$ et al. 2020 ; Zhao et al. 2016). For the population exposure during transportation, the formula $=\pi r^{2} \times$ population density $\times$ travel length (Kargar et al. 2020b; Yu et al. 2020; Zhao et al. 2016) was used to quantify the calculation. Based on the population density and distribution in New York City, it was assumed that the population exposure within $500 \mathrm{~m}$ of the transportation route was considered. For the risk of operating facilities, the probability of accidental risk at the sterilization transfer centers is assumed to be 0.0001 , and the probability of accidental risk at each disposal center and incineration center is 0.0006 ( $Y u$ et al. 2020; Zhao et al. 2016). The population exposure at each facility site was quantified; it was studied using the number of population exposures $=\pi r^{2} \times$ population

Table 2 Number of confirmed COVID-19 cases in New York City (March 4, 2021, to June 4, 2021)

\begin{tabular}{ll}
\hline Day & Confirmed \\
\hline 2021.4 .4 & 919539 \\
2021.5 .4 & 1068496 \\
2021.6 .4 & 1176676 \\
\hline
\end{tabular}


Table 3 Hospital capacity in New York City, USA

\begin{tabular}{|c|c|c|c|c|}
\hline No. & Name & Latitude & Longitude & Beds \\
\hline 1 & Metropolitan Hospital Center & 40.785 & -73.943 & 338 \\
\hline 2 & Bellevue462 First Avenue & 40.740 & -73.976 & 912 \\
\hline 3 & New York-Presbyterian/Queens & 40.715 & -74.011 & 535 \\
\hline 4 & Queens Hospital Center & 40.717 & -73.805 & 269 \\
\hline 5 & Flushing Hospital Medical Center & 40.756 & -73.817 & 299 \\
\hline 6 & Jamaica Hospital Medical Center & 40.701 & -73.817 & 402 \\
\hline 7 & Long Island Jewish Forest Hills & 40.729 & -73.852 & 312 \\
\hline 8 & Long Island Jewish Medical Center & 40.761 & -73.708 & 1025 \\
\hline 9 & Elmhurst Hospital Center & 40.745 & -73.886 & 545 \\
\hline 10 & St. John's Episcopal Hospital So Shore & 40.599 & -73.753 & 257 \\
\hline 11 & Montefiore Medical Center-Henry \& Lucy Moses Div & 40.881 & -73.880 & 816 \\
\hline 12 & $\begin{array}{l}\text { Montefiore Med Center-Jack D Weiler Hosp of A Einstein College } \\
\text { Div }\end{array}$ & 40.849 & -73.846 & 421 \\
\hline 13 & Montefiore Medical Center-Wakefield Hospital & 40.894 & -73.861 & 321 \\
\hline 14 & St. Barnabas Hospital Health System & 40.854 & -73.890 & 422 \\
\hline 15 & BronxCare Hospital Center(a) & 40.848 & -73.910 & 415 \\
\hline 16 & BronxCare Hospital Center(b) & 40.839 & -73.905 & 170 \\
\hline 17 & Jacobi Medical Center & 40.856 & -73.847 & 457 \\
\hline 18 & Calvary Hospital Inc. & 40.848 & -73.844 & 200 \\
\hline 19 & Bellevue Hospital Center & 40.744 & -73.976 & 912 \\
\hline 20 & Harlem Hospital Center & 40.814 & -73.939 & 282 \\
\hline 21 & Henry J. Carter Specialty Hospital & 40.804 & -73.942 & 201 \\
\hline 22 & Hospital for Special Surgery & 40.765 & -73.952 & 215 \\
\hline 23 & Lenox Hill Hospital & 40.775 & -73.961 & 632 \\
\hline 24 & NYU Langone Hospitals & 40.749 & -73.972 & 844 \\
\hline 25 & NYU Langone Orthopedic Hospital & 40.735 & -73.983 & 225 \\
\hline 26 & Rockefeller University Hospital & 40.761 & -73.956 & 40 \\
\hline 27 & Memorial Hospital for Cancer and Allied Diseases & 40.765 & -73.956 & 514 \\
\hline 28 & Mount Sinai Beth Israel & 40.73654 & -73.98374 & 696 \\
\hline 29 & Mount Sinai Hospital & 40.793 & -73.954 & 1139 \\
\hline 30 & New York-Presbyterian Hospital-Allen Hospital & 40.876 & -73.914 & 196 \\
\hline 31 & New York-Presbyterian Hospital—Columbia Presbyterian Center & 40.842 & -73.941 & 1022 \\
\hline 32 & New York-Presbyterian Hospital—New York Weill Cornell Center & 40.765 & -73.954 & 744 \\
\hline 33 & New York-Presbyterian/Lower Manhattan Hospital & 40.710 & -74.005 & 180 \\
\hline 34 & Mount Sinai West & 40.776 & -73.989 & 514 \\
\hline 35 & New York-Presbyterian Brooklyn Methodist Hospital & 40.668 & -73.979 & 591 \\
\hline
\end{tabular}

density in the formula. Population exposure within a radius of $1 \mathrm{~km}$ and $3 \mathrm{~km}$ was considered for the sterilization transfer centers and each disposal center, respectively (Kargar et al. 2020b; Yu et al. 2020; Zhao et al. 2016).

According to the assumptions of Wang et al. (2019b), Yu et al. (2020), and Zhao et al. (2016) and the actual situation of this case, the assignment of each relevant parameter to the sterilization transfer, domestic waste incineration (requisitioned), hazardous waste incineration (requisitioned), newly constructed temporary medical waste disposal, and existing medical waste disposal centers is shown in Table 10.

\section{Computational results}

In this study, a mixed-integer nonlinear programming model with 1023 variables and 280 constraints was developed; it was solved using Lingo 18.0. The case study showed that the maximum benefit of a three-period medical waste reverse logistics recycling network considering disposal capacity bottlenecks under the COVID-19 epidemic in New York City, USA, was $¥ 86,901,390$, as shown in Table 11 .

Table 12 shows the siting strategy for sterilization transfer centers. Table 13 shows the siting strategy for existing medical waste disposal, domestic waste incineration 
Table 4 Amount of hospital medical waste generated per period in New York City

\begin{tabular}{|c|c|c|c|c|}
\hline No. & Names & 2021.4 .4 & 2021.5 .4 & 2021.6.4 \\
\hline 1 & Metropolitan Hospital Center & 91.075 & 105.829 & 116.544 \\
\hline 2 & Bellevue462 First Avenue & 245.742 & 285.550 & 314.461 \\
\hline 3 & New York-Presbyterian/Queens & 144.158 & 167.510 & 184.470 \\
\hline 4 & Queens Hospital Center & 72.483 & 84.225 & 92.752 \\
\hline 5 & Flushing Hospital Medical Center & 80.5677 & 93.618 & 103.096 \\
\hline 6 & Jamaica Hospital Medical Center & 108.321 & 125.867 & 138.611 \\
\hline 7 & Long Island Jewish Forest Hills & 84.070 & 97.688 & 107.579 \\
\hline 8 & Long Island Jewish Medical Center & 276.190 & 320.931 & 353.423 \\
\hline 9 & Elmhurst Hospital Center & 146.852 & 170.641 & 187.918 \\
\hline 10 & St. John's Episcopal Hospital So Shore & 69.250 & 80.468 & 88.614 \\
\hline 11 & Montefiore Medical Center-Henry \& Lucy Moses Div & 219.874 & 255.492 & 281.360 \\
\hline 12 & $\begin{array}{l}\text { Montefiore Med Center-Jack D Weiler Hosp of A Einstein } \\
\text { College Div }\end{array}$ & 113.440 & 131.816 & 145.162 \\
\hline 13 & Montefiore Medical Center-Wakefield Hospital & 86.495 & 100.506 & 110.682 \\
\hline 14 & St. Barnabas Hospital Health System & 113.710 & 132.130 & 145.507 \\
\hline 15 & BronxCare Hospital Center & 111.823 & 129.938 & 143.093 \\
\hline 16 & BronxCare Hospital Center & 45.807 & 53.228 & 58.617 \\
\hline 17 & Jacobi Medical Center & 123.140 & 143.088 & 157.575 \\
\hline 18 & Calvary Hospital Inc. & 53.891 & 62.621 & 68.961 \\
\hline 19 & Bellevue Hospital Center & 245.742 & 285.550 & 314.461 \\
\hline 20 & Harlem Hospital Center & 75.986 & 88.295 & 97.235 \\
\hline 21 & Henry J. Carter Specialty Hospital & 54.160 & 62.934 & 69.305 \\
\hline 22 & Hospital for Special Surgery & 57.933 & 67.317 & 74.133 \\
\hline 23 & Lenox Hill Hospital & 170.295 & 197.881 & 217.916 \\
\hline 24 & NYU Langone Hospitals & 227.419 & 264.259 & 291.014 \\
\hline 25 & NYU Langone Orthopedic Hospital & 60.627 & 70.448 & 77.581 \\
\hline 26 & Rockefeller University Hospital & 10.778 & 12.524 & 13.792 \\
\hline 27 & Memorial Hospital for Cancer and Allied Diseases & 138.499 & 160.935 & 177.229 \\
\hline 28 & Mount Sinai Beth Israel & 187.540 & 217.920 & 239.983 \\
\hline 29 & Mount Sinai Hospital & 306.908 & 356.625 & 392.731 \\
\hline 30 & New York-Presbyterian Hospital-Allen Hospital & 52.813 & 61.368 & 67.581 \\
\hline 31 & New York-Presbyterian Hospital—Columbia Presbyterian Center & 275.382 & 319.992 & 352.389 \\
\hline 32 & New York-Presbyterian Hospital—New York Weill Cornell Center & 200.474 & 232.949 & 256.534 \\
\hline 33 & New York-Presbyterian/Lower Manhattan Hospital & 48.502 & 56.359 & 62.065 \\
\hline 34 & Mount Sinai West & 138.499 & 160.935 & 177.229 \\
\hline 35 & New York-Presbyterian Brooklyn Methodist Hospital & 159.247 & 185.044 & 203.779 \\
\hline
\end{tabular}

Table 5 Alternative sites for sterilization transfer centers

\begin{tabular}{llccc}
\hline No. & Name & Latitude & Longitude & Code \\
\hline 1 & Waste Management-Harlem River Yard Transfer Station & 40.832 & -73.923 & A \\
2 & Staten Island Transfer Station & 40.615 & -74.190 & B \\
3 & Waste Management-Varick Transfer Station & 40.713 & -73.930 & C \\
4 & NYC DSNY Household Special Waste Drop-Off Sites & 40.800 & -73.855 & D \\
5 & New York City Rubbish Removal & 40.872 & -73.845 & E \\
6 & Hamilton Avenue Marine Transfer Station & 40.679 & -73.999 & F \\
\hline
\end{tabular}


Table 6 Alternative sites for existing medical waste disposal centers

\begin{tabular}{lllll}
\hline No. & Name & Latitude & Longitude & Code \\
\hline 1 & Medical Waste Systems Inc. & 40.776 & -73.424 & $\mathrm{H}$ \\
2 & Prestige Medical Waste LLC & 40.763 & -73.681 & $\mathrm{I}$ \\
3 & Approved Storage \& Waste Hauling, & 40.914 & -73.827 & $\mathrm{~J}$ \\
$\quad$ & Inc.-Healthcare Waste & & \\
$\quad$ Management Services & 40.719 & -74.009 & $\mathrm{~L}$ \\
4 & Cyntox Medical Waste Disposal & 40.759 & -73.981 & $\mathrm{M}$ \\
5 & Red Bags Medical Waste & 40.815 & -73.962 & $\mathrm{~N}$ \\
6 & Medical Waste Disposal Service & 40.809 & -73.908 & $\mathrm{O}$ \\
7 & Healthcare Waste Solutions & 40.820 & -73.879 & $\mathrm{P}$ \\
8 & Daniels Health New York-Medical & & & \\
& $\quad$ Waste & 40.873 & -73.825 & $\mathrm{Q}$ \\
\hline
\end{tabular}

(requisitioned), hazardous waste incineration (requisitioned), and newly constructed temporary medical waste disposal centers with a value of 1 if the facility point is selected in period $p$ and 0 otherwise. The results show that in the existing medical waste disposal centers, during period 1 , points I, J, M, N, O, and $\mathrm{P}$ are selected. In the domestic waste incineration centers (requisitioned), during period 1, point $\mathrm{S}$ is selected, and in the hazardous waste incineration centers (requisitioned), during period 1 , point $\mathrm{V}$ is selected. Point $\mathrm{S}$ of the domestic waste incineration centers (requisitioned) and point $\mathrm{V}$ of the hazardous waste incineration centers (requisitioned), which are relatively concentrated in terms of geographical location, were selected for the collaborative disposal of medical waste as the amount of medical waste in period 1 did not reach the maximum disposal capacity of the existing medical waste disposal centers, and points $\mathrm{H}$ and $\mathrm{Q}$ are relatively remote and far away, with high transportation costs and transportation risks.

Due to the continuous increase of patients with COVID-19 during periods 2 and 3 , the continuous increase in the amount of medical waste generated was beyond the maximum disposal capacity of the existing medical waste disposal centers even with all existing centers being put into operation. The selection in period 2 in the domestic waste incineration centers (requisitioned) was point $\mathrm{S}$, and the selection in the hazardous waste incineration centers (requisitioned) was point $U$. In the domestic waste incineration centers (requisitioned) in period

Table 7 Alternative sites for domestic waste incineration centers (requisitioned)

\begin{tabular}{lllll}
\hline No. & Name & Latitude & Longitude & Code \\
\hline 1 & Covanta Babylon Inc. & 40.751 & -73.384 & $\mathrm{R}$ \\
2 & Islip Resource Recovery Agency & 40.753 & -73.216 & $\mathrm{~S}$ \\
3 & Covanta Union, Inc. & 40.625 & -74.269 & $\mathrm{~T}$ \\
\hline
\end{tabular}

Table 8 Alternative sites for hazardous waste incineration centers (requisitioned)

\begin{tabular}{llccc}
\hline No. & Name & Latitude & Longitude & Code \\
\hline 1 & Huntington Recycling Center & 40.889 & -73.410 & U \\
2 & Old Bethpage Solid Waste Disposal & 40.788 & -73.452 & V \\
& Complex & & & \\
\hline
\end{tabular}

3 , points $\mathrm{R}$ and $\mathrm{S}$ are selected, and in the hazardous waste incineration centers (requisitioned) in period 3, point $U$ is selected.

During the three periods of the study, a newly constructed temporary medical waste disposal center, point $\mathrm{X}$, was maintained as emergency disposal centers for medical waste. In the face of a sudden surge in the amount of medical waste, the time to install the temporary new facility can be reduced, and the center can be put into use quickly to reduce the risk of infection.

Tables 14, 15, 16, and 17 show the distribution of medical waste flows between hospitals and sterilization transfer centers, between sterilization transfer centers and existing medical waste disposal centers, between sterilization transfer centers and domestic waste incineration centers (requisitioned), and between sterilization transfer centers and hazardous waste incineration centers (requisitioned). For example, in Table 14, $(1, \mathrm{~A}, 1)$ indicates that the number of shipments from the hospital to the disinfection transfer centers in period 1 is 91.075 tons.

\section{Sensitivity analysis}

This section analyzes the influence of the key parameters on the value of the objective function.

There are three important components, namely, economic cost $(C)$, safety risk $(Z)$, and time urgency $(W)$, in the multiobjective multi-period mixed-integer nonlinear programming model of medical waste recycling network considering disposal capacity bottlenecks under the COVID-19 epidemic proposed in this study.

Assuming that the parameter affecting economic efficiency, safety risk, and time urgency is $\alpha, \beta$, and $\gamma$, respectively, the objective function is as follows:

Table 9 Alternative sites for the newly constructed temporary medical waste disposal centers

\begin{tabular}{llll}
\hline No. & Candidate sites code & Latitude & Longitude \\
\hline 1 & $\mathrm{X}$ & 40.758 & -74.002 \\
2 & $\mathrm{Y}$ & 40.733 & -73.981 \\
\hline
\end{tabular}


Table 10 Values assigned to each parameter in the various centers considered in the case study

\begin{tabular}{|c|c|c|c|}
\hline Parameters & Variable & Value & Unit \\
\hline Fixed cost of establishing sterilization transfer centers & $F C_{j}^{p}$ & 77400 & Dollar \\
\hline Fixed cost of domestic waste incineration centers (requisitioned) & $F C_{d}^{p}$ & 46440 & Dollar \\
\hline Fixed cost of hazardous waste incineration centers (requisitioned) & $F C_{h}^{p}$ & 46440 & Dollar \\
\hline Fixed costs of newly constructed temporary medical waste disposal centers & $F C_{t}^{p}$ & 619200 & Dollar \\
\hline Fixed costs of closure of sterilization transfer centers & $f_{c}^{p}$ & 11610 & Dollar \\
\hline Fixed costs of closure of newly constructed temporary medical waste disposal centers & $f c_{t}^{p}$ & 11610 & Dollar \\
\hline Operating costs of sterilization transfer centers & $O C_{j}^{p}$ & 15480 & Dollar \\
\hline Operating costs of domestic waste incineration centers (requisitioned) & $O C_{d}^{p}$ & 30960 & Dollar \\
\hline Operating costs of hazardous waste incineration centers (requisitioned) & $O C_{h}^{p}$ & 30960 & Dollar \\
\hline Operating costs of newly constructed temporary medical waste disposal centers & $O C_{t}^{p}$ & 30960 & Dollar \\
\hline Operating cost of existing medical waste disposal centers & $O C_{e}^{p}$ & 46440 & Dollar \\
\hline Unit disposal cost of sterilization transfer centers & $T C_{j}^{p}$ & 232.2 & Dollar/ton \\
\hline Unit disposal cost of domestic waste incineration centers (requisitioned) & $T C_{d}^{p}$ & 216.72 & Dollar/ton \\
\hline Unit disposal cost of hazardous waste incineration centers (requisitioned) & $T C_{h}^{p}$ & 216.72 & Dollar/ton \\
\hline Unit disposal cost of newly constructed temporary medical waste disposal centers & $T C_{t}^{p}$ & 309.6 & Dollar/ton \\
\hline Unit disposal cost of existing medical waste disposal centers & $T C_{e}^{p}$ & 185.76 & Dollar/ton \\
\hline Disinfection cost of sterilization transfer centers & $D C_{j}^{p}$ & 77.4 & Dollar/ton \\
\hline Maximum processing capacity of sterilization transfer centers & $C A_{j}^{p}$ & 1704 & Ton/period \\
\hline Maximum processing capacity of domestic waste incineration centers (requisitioned) & $C A_{d}^{p}$ & 180 & Ton/period \\
\hline Maximum processing capacity of hazardous waste incineration centers (requisitioned) & $C A_{h}^{p}$ & 236 & Ton/period \\
\hline Maximum processing capacity of newly constructed temporary medical waste disposal centers & $C A_{t}^{p}$ & 300 & Ton/period \\
\hline Maximum processing capacity of existing medical waste disposal centers & $C A_{e}^{p}$ & 600 & Ton/period \\
\hline Maximum number of construction of sterilization transfer centers & $M P_{j}$ & 5 & \\
\hline Maximum number of domestic waste incineration centers (requisitioned) & $M P_{d}$ & 2 & \\
\hline Maximum number of hazardous waste incineration centers (requisitioned) & $M P_{h}$ & 1 & \\
\hline Maximum number of newly constructed temporary medical waste disposal centers & $M P_{t}$ & 1 & \\
\hline
\end{tabular}

$\min F=\alpha C+\beta Z+\gamma W$

Changes in each of these parameters can have a significant impact on the medical waste recycling network under the COVID-19 epidemic. A sensitivity analysis of these parameters would be beneficial for relevant government departments to be able to develop realistic guidance or regulatory policies quickly and timely to respond to emergencies. We conducted

\section{Table 11 Solutions}

\begin{tabular}{ll}
\hline Optional solution found & Profit (dollar) \\
\hline Objective value & 13452335 \\
Objective bound & 13452335 \\
Extended solver steps & 0 \\
Total solver iterations & 2362 \\
Elapsed runtime seconds & 27.68 \\
Model class & MINLP \\
Solver type & Global \\
\hline
\end{tabular}

a sensitivity experiment by expanding or reducing each parameter value to test the impact of parameter changes on the overall target. For each parameter, there were three different rates of change, namely $0.5,1$, and 1.5 (Wang et al. 2019b), as shown in the third column of Table 18. The experimental group used $0.5,1$, and 1.5 as parameter rate changes corresponding to each parameter; the remaining two parameters were set to a unit value of 1 .

Thus, there are $3 \times 3=9$ experimental instances.

The nine experimental examples were solved separately, and the values of the optimization objective function obtained
Table 12 Selection scheme of sterilization transfer centers

\begin{tabular}{lllllll}
\hline Period & \multicolumn{6}{c}{ Sterilization transfer centers } \\
\hline$p=1$ & A & B & C & D & E & F \\
& 1 & 0 & 0 & 1 & 1 & 1 \\
$p=2$ & A & B & C & D & E & F \\
& 0 & 0 & 1 & 1 & 1 & 1 \\
$p=3$ & A & B & C & D & E & F \\
& 0 & 0 & 1 & 1 & 1 & 1 \\
\hline
\end{tabular}


Table 13 Site selection scheme

Period Disposal centers

$\begin{array}{lllllllllllllllll}p=1 & \mathrm{H} & \mathrm{I} & \mathrm{J} & \mathrm{L} & \mathrm{M} & \mathrm{N} & \mathrm{O} & \mathrm{P} & \mathrm{Q} & \mathrm{R} & \mathrm{S} & \mathrm{T} & \mathrm{U} & \mathrm{V} & \mathrm{X} & \mathrm{Y}\end{array}$

$\begin{array}{llllllllllllllll}0 & 1 & 1 & 1 & 1 & 1 & 1 & 1 & 0 & 0 & 1 & 0 & 0 & 1 & 1 & 0\end{array}$

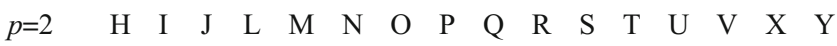

$\begin{array}{llllllllllllllll}1 & 1 & 1 & 1 & 1 & 1 & 1 & 1 & 1 & 0 & 1 & 0 & 1 & 0 & 1 & 0\end{array}$

$\begin{array}{lllllllllllllllll}p=3 & \mathrm{H} & \mathrm{I} & \mathrm{J} & \mathrm{L} & \mathrm{M} & \mathrm{N} & \mathrm{O} & \mathrm{P} & \mathrm{Q} & \mathrm{R} & \mathrm{S} & \mathrm{T} & \mathrm{U} & \mathrm{V} & \mathrm{X} & \mathrm{Y}\end{array}$

$\begin{array}{llllllllllllllll}1 & 1 & 1 & 1 & 1 & 1 & 1 & 1 & 1 & 1 & 1 & 0 & 1 & 0 & 1 & 0\end{array}$

are listed in Table 18 and Figure 3. The sensitivity analysis of the three parameters led to the following three findings:

(1) From Table 18 and Figure 3, it can be seen that the parameter $\alpha$ is positively correlated with the value of the objective function, that is, the larger the parameter $\alpha$, the larger is the value of the objective function. It can be concluded that the change in parameter $\alpha$ has a significant impact on the performance of the medical waste recycling network during the COVID-19 epidemic. This significant change in economic cost may make companies focus too much on economic benefits and ignore other factors, such as safety risks and time urgency, when making decisions about medical waste recycling networks under the COVID-19 epidemic.

(2) The effect of the change in parameter $\beta$ on the performance of the medical waste recycling network under the COVID-19 epidemic is stage-specific. The overall objective function value increased when the rate of change was 0.5 . When the rate of change was 1 and 1.5 , there was almost no change in the performance of the network. Due to the highly infectious nature of medical waste in the COVID-19 outbreak, decision makers need to focus on risk control issues in the design of medical waste recycling networks, and attempt to select less densely populated roadways for transporting medical waste as well as less densely populated facilities for disposal of medical waste. In some cases, a reduction in safety risk can lead to an increase in the overall objective function value and a decrease in the overall network performance.

(3) The variation in the parameter $\gamma$ creates a valley in the overall objective function value, that is, when the rate of change is 0.5 and 1.5 , the overall objective function value is increased. When the rate of change is 1 , the overall objective function value is lower. When making decisions about the medical waste recycling network under the COVID-19 epidemic, decision makers need to control this parameter to achieve a balance between transport distance and population exposure density so that the overall objective function value is maintained at a low level.
Table 14 Traffic distribution from hospitals to sterilization transfer centers

\begin{tabular}{|c|c|c|c|c|c|}
\hline Traffic & Value & Traffic & Value & Traffic & Value \\
\hline$(1, \mathrm{~A}, 1)$ & 91.075 & $(1, \mathrm{D}, 2)$ & 105.829 & $(1, \mathrm{D}, 3)$ & 116.544 \\
\hline$(2, \mathrm{~F}, 1)$ & 245.742 & $(2, \mathrm{~F}, 2)$ & 285.55 & $(2, \mathrm{~F}, 3)$ & 314.461 \\
\hline$(3, F, 1)$ & 144.158 & $(3, \mathrm{~F}, 2)$ & 167.51 & $(3, F, 3)$ & 184.47 \\
\hline$(4, D, 1)$ & 72.483 & $(4, D, 2)$ & 84.225 & $(4, \mathrm{D}, 3)$ & 92.752 \\
\hline$(5, \mathrm{D}, 1)$ & 80.568 & $(5, \mathrm{D}, 2)$ & 93.618 & $(5, \mathrm{D}, 3)$ & 103.096 \\
\hline$(6, D, 1)$ & 108.321 & $(6, \mathrm{D}, 2)$ & 125.867 & $(6, \mathrm{D}, 3)$ & 138.611 \\
\hline$(7, D, 1)$ & 84.07 & $(7, D, 2)$ & 97.688 & $(7, D, 3)$ & 107.579 \\
\hline$(8, D, 1)$ & 276.19 & $(8, \mathrm{D}, 2)$ & 158.339 & $(8, \mathrm{D}, 3)$ & 346.89 \\
\hline$(8, \mathrm{E}, 2)$ & 162.592 & $(8, \mathrm{E}, 3)$ & 6.533 & $(9, \mathrm{D}, 1)$ & 146.852 \\
\hline$(9, \mathrm{D}, 2)$ & 170.641 & $(9, \mathrm{D}, 3)$ & 187.918 & $(10, \mathrm{~F}, 1)$ & 69.25 \\
\hline$(10, C, 2)$ & 70.043 & $(10, F, 2)$ & 10.425 & $(10, C, 3)$ & 88.614 \\
\hline$(11, \mathrm{E}, 1)$ & 219.874 & $(11, \mathrm{E}, 2)$ & 255.492 & $(11, \mathrm{E}, 3)$ & 281.36 \\
\hline$(12, \mathrm{E}, 1)$ & 113.44 & $(12, \mathrm{E}, 2)$ & 131.816 & $(12, \mathrm{E}, 3)$ & 145.162 \\
\hline$(13, \mathrm{E}, 1)$ & 86.495 & $(13, \mathrm{E}, 2)$ & 100.506 & $(13, \mathrm{E}, 3)$ & 110.682 \\
\hline$(14, \mathrm{E}, 1)$ & 113.71 & $(14, \mathrm{E}, 2)$ & 132.13 & $(14, \mathrm{E}, 3)$ & 145.507 \\
\hline$(15, \mathrm{~A}, 1)$ & 111.823 & $(15, \mathrm{E}, 2)$ & 129.938 & $(15, \mathrm{E}, 3)$ & 143.093 \\
\hline$(16, \mathrm{~A}, 1)$ & 45.807 & $(16, \mathrm{E}, 2)$ & 53.228 & $(16, \mathrm{E}, 3)$ & 58.617 \\
\hline$(17, \mathrm{E}, 1)$ & 123.14 & $(17, \mathrm{E}, 2)$ & 143.088 & $(17, \mathrm{E}, 3)$ & 157.575 \\
\hline$(18, \mathrm{E}, 1)$ & 53.891 & $(18, \mathrm{E}, 2)$ & 62.621 & $(18, \mathrm{E}, 3)$ & 68.961 \\
\hline$(19, \mathrm{~F}, 1)$ & 245.742 & $(19, F, 2)$ & 285.55 & $(19, \mathrm{~F}, 3)$ & 314.461 \\
\hline$(20, \mathrm{~A}, 1)$ & 75.986 & $(20, \mathrm{E}, 2)$ & 88.295 & $(20, \mathrm{E}, 3)$ & 97.235 \\
\hline$(21, \mathrm{~A}, 1)$ & 54.16 & $(21, \mathrm{E}, 2)$ & 62.934 & $(21, \mathrm{E}, 3)$ & 69.305 \\
\hline$(22, \mathrm{~A}, 1)$ & 57.933 & $(22, \mathrm{D}, 2)$ & 67.317 & $(22, \mathrm{C}, 3)$ & 74.133 \\
\hline$(23, \mathrm{~A}, 1)$ & 170.295 & $(23, \mathrm{D}, 2)$ & 197.881 & $(23, C, 3)$ & 0.037 \\
\hline$(23, \mathrm{D}, 3)$ & 217.879 & $(24, F, 1)$ & 227.419 & $(24, F, 2)$ & 264.259 \\
\hline$(24, C, 3)$ & 161.043 & $(24, F, 3)$ & 129.971 & $(25, \mathrm{~F}, 1)$ & 60.627 \\
\hline$(25, \mathrm{~F}, 2)$ & 70.448 & $(25, \mathrm{~F}, 3)$ & 77.581 & $(26, \mathrm{~A}, 1)$ & 10.778 \\
\hline$(26, C, 2)$ & 12.524 & $(26, C, 3)$ & 13.792 & $(27, \mathrm{~A}, 1)$ & 138.499 \\
\hline$(27, \mathrm{C}, 2)$ & 147.914 & $(27, \mathrm{D}, 2)$ & 13.021 & $(27, C, 3)$ & 177.229 \\
\hline$(28, \mathrm{~F}, 1)$ & 187.54 & $(28, F, 2)$ & 217.92 & $(28, F, 3)$ & 239.983 \\
\hline$(29, \mathrm{~A}, 1)$ & 306.908 & $(29, \mathrm{D}, 2)$ & 356.625 & $(29, D, 3)$ & 392.731 \\
\hline$(30, A, 1)$ & 26.381 & $(30, \mathrm{E}, 1)$ & 26.432 & $(30, \mathrm{E}, 2)$ & 61.368 \\
\hline$(30, E, 3)$ & 67.581 & $(31, A, 1)$ & 275.382 & $(31, \mathrm{E}, 2)$ & 319.992 \\
\hline$(31, \mathrm{E}, 3)$ & 352.389 & $(32, \mathrm{~A}, 1)$ & 200.474 & $(32, \mathrm{D}, 2)$ & 232.949 \\
\hline$(32, \mathrm{C}, 3)$ & 256.534 & $(33, \mathrm{~F}, 1)$ & 48.502 & $(33, \mathrm{~F}, 2)$ & 56.359 \\
\hline$(33, F, 3)$ & 62.065 & $(34, \mathrm{~A}, 1)$ & 138.499 & $(34, F, 2)$ & 160.935 \\
\hline$(34, F, 3)$ & 177.229 & $(35, \mathrm{~F}, 1)$ & 159.247 & $(35, \mathrm{~F}, 2)$ & 185.044 \\
\hline$(35, F, 3)$ & 203.779 & - & - & - & - \\
\hline
\end{tabular}

In summary, medical waste under the COVID-19 epidemic has a unique nature, and the process of recycling and disposal should take into full consideration the safety risks and time urgency of medical waste, rather than the economic cost alone as an indicator. The USA has promulgated several mandatory 
Table 15 Traffic distribution from sterilization transfer centers to existing medical waste disposal centers

\begin{tabular}{llllll}
\hline Traffic & Value & Traffic & Value & Traffic & Value \\
\hline$(\mathrm{A}, \mathrm{O}, 1)$ & 600 & $(\mathrm{~A}, \mathrm{P}, 1)$ & 600 & $(\mathrm{~A}, \mathrm{Q}, 1)$ & 504 \\
$(\mathrm{C}, \mathrm{L}, 2)$ & 230.481 & $(\mathrm{C}, \mathrm{L}, 3)$ & 600 & $(\mathrm{C}, \mathrm{J}, 3)$ & 171.382 \\
$(\mathrm{D}, \mathrm{I}, 1)$ & 168.484 & $(\mathrm{D}, \mathrm{I}, 2)$ & 600 & $(\mathrm{D}, \mathrm{I}, 3)$ & 600 \\
$(\mathrm{D}, \mathrm{M}, 1)$ & 600 & $(\mathrm{D}, \mathrm{M}, 2)$ & 600 & $(\mathrm{D}, \mathrm{M}, 3)$ & 600 \\
$(\mathrm{D}, \mathrm{Q}, 2)$ & 276 & $(\mathrm{D}, \mathrm{Q}, 3)$ & 276 & $(\mathrm{E}, \mathrm{I}, 1)$ & 431.516 \\
$(\mathrm{E}, \mathrm{J}, 1)$ & 227.773 & $(\mathrm{E}, \mathrm{H}, 2)$ & 126.481 & $(\mathrm{E}, \mathrm{H}, 3)$ & 487.382 \\
$(\mathrm{E}, \mathrm{L}, 1)$ & 77.693 & $(\mathrm{E}, \mathrm{J}, 2)$ & 600 & $(\mathrm{E}, \mathrm{J}, 3)$ & 428.618 \\
$(\mathrm{E}, \mathrm{L}, 2)$ & 369.519 & $(\mathrm{E}, \mathrm{O}, 2)$ & 600 & $(\mathrm{E}, \mathrm{O}, 3)$ & 600 \\
$(\mathrm{~F}, \mathrm{~J}, 1)$ & 372.227 & $(\mathrm{~F}, \mathrm{Q}, 2)$ & 324 & $(\mathrm{~F}, \mathrm{~N}, 1)$ & 600 \\
$(\mathrm{~F}, \mathrm{~N}, 2)$ & 600 & $(\mathrm{~F}, \mathrm{~N}, 3)$ & 600 & $(\mathrm{~F}, \mathrm{P}, 2)$ & 600 \\
$(\mathrm{~F}, \mathrm{P}, 3)$ & 600 & $(\mathrm{~F}, \mathrm{Q}, 3)$ & 324 & - & - \\
\hline
\end{tabular}

laws and regulations and established a strict sterilization process. Enterprises should recycle medical waste in strict accordance with these laws and regulations, which can make medical waste have minimal impact on people and the environment, improve the image of these enterprises in society, and generate great social benefits while gaining huge economic benefits.

\section{Conclusion and insight}

This study aims to address the problem of optimizing the siting of reverse logistics network facilities when the amount of medical waste exceeds the disposal capacity of existing medical waste disposal centers. This is a key issue in the safe and healthy management of medical waste under the COVID-19 epidemic. First, a multiperiod dynamic site selection model with the objectives of minimum cost, safety risk, and time is established for the infrastructure of medical waste reverse logistics recycling, including hospitals, domestic waste incineration centers (requisitioned), hazardous waste incineration centers (requisitioned), newly constructed temporary medical waste disposal centers, existing medical waste disposal centers, and harmless disposal centers. Second, this study conducted an empirical study on the recycling of medical waste under the COVID-19 epidemic in New York City, USA. Based on historical data and third-

Table 16 Traffic distribution from sterilization transfer centers to domestic waste incineration centers (requisitioned)

\begin{tabular}{llllll}
\hline Traffic & Value & Traffic & Value & Traffic & Value \\
\hline (F,S 1$)$ & 180 & $(\mathrm{~F}, \mathrm{~S}, 2)$ & 180 & $(\mathrm{E}, \mathrm{R}, 3)$ & 180.00 \\
\hline
\end{tabular}

Table 17 Traffic distribution from sterilization transfer centers to hazardous waste incineration centers (requisitioned)

\begin{tabular}{llllll}
\hline Traffic & Value & Traffic & Value & Traffic & Value \\
\hline$(\mathrm{F}, \mathrm{V}, 1)$ & 236 & $(\mathrm{D}, \mathrm{U}, 2)$ & 228 & $(\mathrm{D}, \mathrm{U}, 3)$ & 228 \\
$(\mathrm{E}, \mathrm{U}, 2)$ & 8 & $(\mathrm{E}, \mathrm{U}, 3)$ & 8 & - & - \\
\hline
\end{tabular}

order polynomial functions, the amount of medical waste recycling was predicted for the next 3 months. This study analyzes the locations of these potential facilities and the distribution of flows in the medical waste reverse logistics recycling network in New York City, USA, for each period. Finally, the impact of increasing or decreasing the different weights of three factors-economic efficiency, safety risk, and time urgency - on the location decision of the medical waste reverse logistics network under the COVID-19 epidemic was investigated.

The research results are summarized as follows. (1) An optimization method combining predictive and mixedinteger nonlinear programming models was used to construct a multi-period, multi-objective dynamic site selection model for determining the location of each facility in the medical waste reverse logistics network and the distribution of medical waste flows under the COVID-19 epidemic considering treatment capacity bottlenecks. (2) A model was developed to consider safety risks; time urgency; newly constructed temporary medical waste disposal, domestic waste incineration (requisitioned), and hazardous waste incineration (requisitioned) centers; and other synergistic facilities to achieve the goals of lowest cost, least safety risk, and shortest time. (3) A sensitivity analysis of the parameters in the medical waste reverse logistics recycling network under the COVID-19 epidemic was conducted to test the proposed factors affecting the performance of the medical waste reverse logistics network under the COVID-19 epidemic. Although the

Table 18 Values of parameters $\alpha, \beta$, and $\gamma$ under different the change rates

\begin{tabular}{lllllll}
\hline Parameters & Instance no. & Change rate & $\alpha$ & $\beta$ & $\gamma$ & Value(dollar) \\
\hline$\alpha$ & 1 & 0.5 & 0.5 & 1 & 1 & 6843635 \\
$C$ & 2 & 1 & 1 & 1 & 1 & 13452335 \\
& 3 & 1.5 & 1.5 & 1 & 1 & 20052250 \\
$\beta$ & 4 & 0.5 & 1 & 0.5 & 1 & 13947470 \\
$Z$ & 5 & 1 & 1 & 1 & 1 & 13452335 \\
& 6 & 1.5 & 1 & 1.5 & 1 & 13609155 \\
$\gamma$ & 7 & 0.5 & 1 & 1 & 0.5 & 13839713 \\
$W$ & 8 & 1 & 1 & 1 & 1 & 13452335 \\
& 9 & 1.5 & 1 & 1 & 1.5 & 14193166 \\
\hline
\end{tabular}


Fig. 3 Effect of changes in parameters $\alpha, \beta$, and $\gamma$ on the value of the objective function

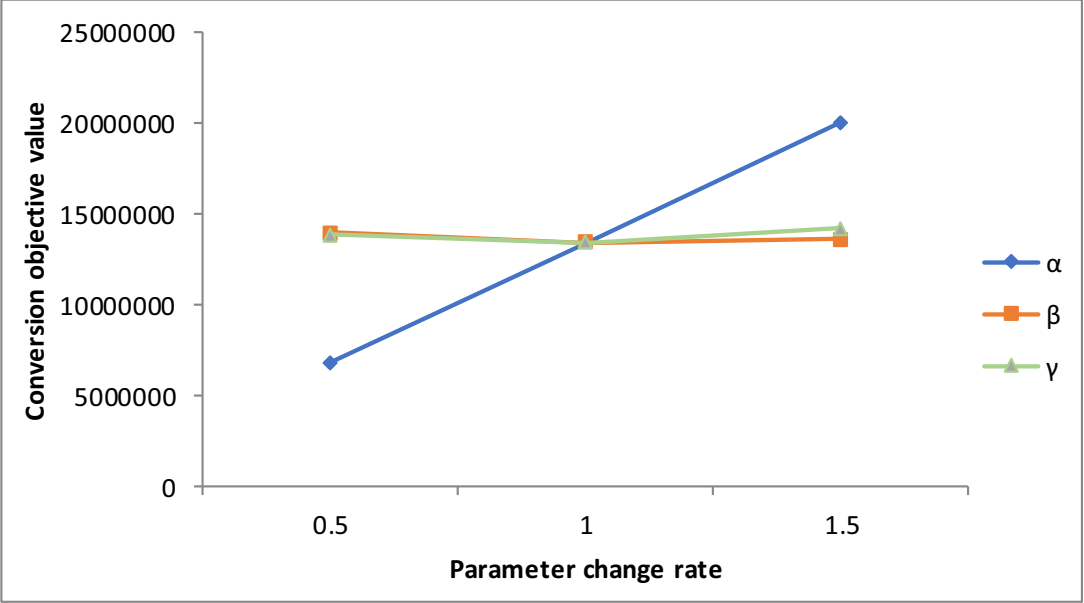

impact of economic cost is much larger than the impact of time and safety risk in the objective function, economic cost, risk control, and rapid processing are critical for the recycling of medical waste during the COVID-19 epidemic.

The study on the optimization of medical waste recycling networks considering disposal capacity bottlenecks under COVID-19 epidemic facilitates the focus on the reverse logistics management of medical waste under COVID-19. This study uses a combination of third-order polynomial function prediction and mixed-integer nonlinear programming models, and considers safety risks, economic benefits, and time urgency to facilitate the improvement of the design, operation, and management of medical waste reverse logistics recycling networks considering disposal capacity bottlenecks under the COVID19 epidemic. It provides possible solutions for maintaining the balance of safety risks, economic benefits, and time urgency under the COVID-19 epidemic, and affords some reference for decision makers on whether to prioritize synergistic facilities such as domestic waste incineration centers, hazardous waste incineration centers, or newly constructed temporary medical waste disposal centers in emergencies. The study also provides guidance for different regions to build a reverse logistics recycling network for the efficient treatment of medical waste under public health emergencies.

However, owing to the complexity of such a network under the COVID-19 epidemic, there is still a need for continuous improvement and addition to this area in future studies. In this study, the prioritization of medical waste disposal, the medical waste generated by home isolation, and the uncertainty of medical waste transportation vehicle times were not fully considered. Related issues will be considered and quantified in future studies. Although this study has certain shortcomings, it still provides the following insights:
(1) In the face of a surge of highly infectious medical waste during public health emergencies, it is important to establish a medical waste reverse logistics recycling network by temporarily requisitioning synergistic facilities, such as domestic waste incineration centers and hazardous waste incineration centers, and constructing new temporary medical waste disposal centers.

(2) In emergencies, the requisition of synergistic facilities and new temporary medical waste disposal centers can handle the surge of medical waste in a short period of time and control the risk of infection.

(3) Compared with new temporary medical waste disposal centers, the requisition of synergistic facilities such as domestic waste incineration centers and hazardous waste incineration centers can reduce the time, construction, and facility closure costs. Simultaneously, the risk of infection and environmental pollution can be reduced to a certain extent.

Author contribution All authors contributed to the study conception and design. Material preparation was performed by [WXY], and data collection and analysis were performed by [SYC], [HH], [MXY], and [ZYJ]. Supervision and instruction were performed by $[\mathrm{HH}]$. The first draft of the manuscript was written by [MXY] and all authors commented on previous versions of the manuscript. All authors read and approved the final manuscript.

Funding This research was supported by the National Social Science Foundation of China (grant no. 20BGL200).

Data availability The datasets generated and analyzed in the current study can be accessed directly from this paper.

\section{Declarations}

Ethics approval and consent to participate Not applicable

Consent for publication Not applicable

Conflict of interest The authors declare no competing interests. 


\section{References}

Ahlaqqach M, Benhra J, Mouatassim S, Lamrani S (2020) Closed loop location routing supply chain network design in the end of life pharmaceutical products. SCFIJ 21:79-92. https://doi.org/10.1080/ 16258312.2020 .1752112

Akhtar IuH (2020): Understanding the CoVID-19 pandemic curve through statistical approach. medRxiv https://doi.org/10.1101/ 2020.04.06.20055426

Alizadeh M, Makui A, Paydar MM (2020) Forward and reverse supply chain network design for consumer medical supplies considering biological risk. Comput Ind Eng 140:106229. https://doi.org/10. 1016/j.cie.2019.106229

Amar LA, Taha AA, Mohamed MY (2020) Prediction of the final size for COVID-19 epidemic using machine learning: a case study of Egypt. Infectious Disease Modelling 5:622-634. https://doi.org/10.1016/j. idm.2020.08.008

Amin SH, Baki F (2017) A facility location model for global closed-loop supply chain network design. Appl Math Model 41:316-330. https://doi.org/10.1016/j.apm.2016.08.030

Budak A, Ustundag A (2017) Reverse logistics optimisation for waste collection and disposal in health institutions: the case of Turkey. Int J Logist-Res App 20:322-341. https://doi.org/10.1080/13675567. 2016.1234595

Cao F, Guo J, Liu X (2017) A study on the joint construction of multicycle pharmaceutical reverse logistics network considering carbon emission. Journal of East China Normal University (Natural Science)(in Chinese): $52-60$

Caunhye AM, Nie X, Pokharel S (2012) Optimization models in emergency logistics: A literature review. Socio-Econ Plan Sci 46:4-13. https://doi.org/10.1016/j.seps.2011.04.004

Choudhary A, Sarkar S, Settur S, Tiwari MK (2015) A carbon market sensitive optimization model for integrated forward-reverse logistics. Int J Prod Econ 164:433-444. https://doi.org/10.1016/j.ijpe. 2014.08.015

Ene S, Öztürk N (2015) Network modeling for reverse flows of end-oflife vehicles. Waste Manag 38:284-296. https://doi.org/10.1016/j. wasman.2015.01.007

Environment MoEa (2010): National hazardous waste business license issued http://www.mee.gov.cn/ywgz/gtfwyhxpgl/wxfw/201604/ P020160424387683597032.pdf

Environment MoEa (2019): Leduc District Domestic Waste Landfill Treatment Plant http://www.mee.gov.cn/home/ztbd/rdzl/sskf/kfss/ qhs/dep/201909/t20190930_736351.shtml

Fleischmann M, Beullens P, Bloemhof-Ruwaard JM, Van Wassenhove LN (2001) The impact of product recovery on logistics network design. Prod Oper Manag 10:156-173. https://doi.org/10.1111/j. 1937-5956.2001.tb00076.x

Hajiaghaei-Keshteli M, Fathollahi Fard AM (2018) Sustainable closedloop supply chain network design with discount supposition. Neural Comput \& Applic 31:5343-5377. https://doi.org/10.1007/s00521018-3369-5

Hao H, Wang Z, Lin H, Zhang Q, Huang M, Zhu J, Liu F, Li T (2017) Fifth profit source:The business value and mode of reverse logistics in China. Logistics Technology (in Chinese) 36:47-50

Hao H, Zhang Q, Wang Z (2018a) Evaluation of the feasibility of reverse logistics of end-of-life car batteries-based on improved fuzzy neural network. China Business and Market (in Chinese) 32:15-24. https:// doi.org/10.14089/j.cnki.cn11-3664/f.2018.06.002

Hao H, Zhang Q, Wang Z, Zhang J (2018b) Forecasting the number of end-of-life vehicles using a hybrid model based on grey model and artificial neural network. J Clean Prod 202:684-696. https://doi.org/ 10.1016/j.jclepro.2018.08.176
Hao H, Zhang J, Zhang Q, Yao L, Sun Y (2019) Improved gray neural network model for healthcare waste recycling forecasting. J Comb Optim. https://doi.org/10.1007/s10878-019-00482-2

Hao H, Zhang J, Zhang Q (2020) Countermeasures for the development of reverse logistics of power battery recycling in China under the circular economy. Ecological Economy (in Chinese) 36:86-91

Health N (2021): Cumulative daily number of patients on COVID-19 in New York City, USA https://wwwl.nyc.gov/site/doh/covid/covid19-data.page

Huang J, Liu L (2021) Prediction of ground settlement in Tianjin port based on polynomial regression model. Shanxi Architecture 47:6769. https://doi.org/10.13719/j.cnki.cn14-1279/tu.2021.02.025

Huo Q, Guo J (2020) Multi-objective, multi-cycle sustainable recycling network optimization for medical waste. Journal of University of Shanghai for Science and Technology 42:479-487. https://doi.org/ 10.13255/j.cnki.jusst.20191115001

Janagi R, Shah J, Maheshwari D (2015) Scenario of management of medical waste in US and UK: a review. Journal of Global Trends in Pharmaceutical Sciences

Jing S, Chen N (2015) Research and application of reverse logistics network optimization of expired drugs. Journal of Nanjing Radio \& TV University (in Chinese): 90-94

Kampf G, Todt D, Pfaender S, Steinmann E (2020) Persistence of coronaviruses on inanimate surfaces and their inactivation with biocidal agents. J Hosp Infect 104:246-251. https://doi.org/10.1016/j. jhin.2020.01.022

Kargar S, Paydar MM, Safaei AS (2020a) A reverse supply chain for medical waste: a case study in Babol healthcare sector. Waste Manag 113:197-209. https://doi.org/10.1016/j.wasman.2020.05. 052

Kargar S, Pourmehdi M, Paydar MM (2020b) Reverse logistics network design for medical waste management in the epidemic outbreak of the novel coronavirus (COVID-19). Sci Total Environ 746:141183. https://doi.org/10.1016/j.scitotenv.2020.141183

Liu M, Li Y, Cao J, Zhang D (2020a) Optimal design of emergency logistics network based on service level in sudden epidemic environment. Chinese Journal of Management Science (in Chinese) 28: 11-20. https://doi.org/10.16381/j.cnki.issn1003-207x.2020.03.002

Liu Z, Li Z, Chen W, Zhao Y, Yue H, Wu Z (2020b) Path optimization of medical waste transport routes in the emergent public health event of covid-19: a hybrid optimization algorithm based on the immune-ant colony algorithm. Int J Env Res Pub He 17:1-18. https://doi.org/10. 3390/ijerph17165831

Orihuel E, Sapena J, Navarro-Ortiz J (2021) An empirical algorithm for COVID-19 nowcasting and short-term forecast in Spain: a kinematic approach. A S I 4. https://doi.org/10.3390/asi4010002

Profiles NH (2021): Number of hospital beds in New York State, USA https://profiles.health.ny.gov/hospital/bed type/Total+Beds

Rezaei-Malek M, Tavakkoli-Moghaddam R, Zahiri B, Bozorgi-Amiri A (2016) An interactive approach for designing a robust disaster relief logistics network with perishable commodities. Comput Ind Eng 94: 201-215. https://doi.org/10.1016/j.cie.2016.01.014

Sarkodie SA, Owusu PA (2021) Impact of COVID-19 pandemic on waste management. Environ Dev Sustain 23:7951-7960. https:// doi.org/10.1007/s10668-020-00956-y

Sharma HB, Vanapalli KR, Cheela VRS, Ranjan VP, Jaglan AK, Dubey B, Goel S, Bhattacharya J (2020) Challenges, opportunities, and innovations for effective solid waste management during and post COVID-19 pandemic. Resour Conserv Recycl 162:105052. https:// doi.org/10.1016/j.resconrec.2020.105052

Singh N, Tang Y, Ogunseitan OA (2020) Environmentally sustainable management of used personal protective equipment. Environ Sci Technol 54:8500-8502. https://doi.org/10.1021/acs.est.0c03022

Stock JR (1992): Reverse logistics: white paper. Council of Logistics Management 
Sun H, Da Q (2009) Study on the location of integrated manufacturing/ remanufacturing logistics network facilities. Comput Integr Manuf 15:362-368. https://doi.org/10.13196/j.cims.2009.02.156.sunh.013

Tirkolaee EB, Abbasian P, Weber G-W (2021) Sustainable fuzzy multitrip location-routing problem for medical waste management during the COVID-19 outbreak. Sci Total Environ 756:143607. https://doi. org/10.1016/j.scitotenv.2020.143607

Wang Y, Huang Y (2015) Design of reverse logistics network for expired drugs considering residents' choice behavior. Journal of Central China Normal University(Natural Sciences) (in Chinese) 49:5259. https://doi.org/10.19603/j.cnki.1000-1190.2015.01.011

Wang Z, Hao H, Gao F, Zhang Q, Zhang J, Zhou Y (2019a) Multiattribute decision making on reverse logistics based on DEATOPSIS: a study of the Shanghai End-of-life vehicles industry. J Clean Prod 214:730-737. https://doi.org/10.1016/j.jclepro.2018. 12.329

Wang Z, Huang L, He CX (2019b) A multi-objective and multi-period optimization model for urban healthcare waste's reverse logistics network design. J Comb Optim. https://doi.org/10.1007/s10878019-00499-7

Xiao Z, Sun J, Shu W, Wang T (2019) Location-allocation problem of reverse logistics for end-of-life vehicles based on the measurement of carbon emissions. Comput Ind Eng 127:169-181. https://doi.org/ 10.1016/j.cie.2018.12.012

Yang L, Yu X, Wu X, Wang J, Yan X, Jiang S, Chen Z (2021) Emergency response to the explosive growth of health care wastes during COVID-19 pandemic in Wuhan, China. Resour Conserv
Recycl 164:105074. https://doi.org/10.1016/j.resconrec.2020. 105074

Yu H, Sun X, Solvang WD, Zhao X (2020) Reverse logistics network design for effective management of medical waste in epidemic outbreaks: insights from the coronavirus disease 2019 (COVID-19) outbreak in Wuhan (China). Int J Env Res Pub He 17. https://doi. org/10.3390/ijerph17051770

Zhang J, Liu H, Yu G, Ruan J, Chan FTS (2019) A three-stage and multiobjective stochastic programming model to improve the sustainable rescue ability by considering secondary disasters in emergency logistics. Comput Ind Eng 135:1145-1154. https://doi.org/10.1016/j. cie.2019.02.003

Zhang L, Li D, Ren J (2020) COVID-19 propagation analysis of a multistage dynamic time lag dynamics model. Geomatics and Information Science of Wuhan University (in Chinese) 45:658666. https://doi.org/10.13203/j.whugis20200206

Zhao J, Huang L, Lee D-H, Peng Q (2016) Improved approaches to the network design problem in regional hazardous waste management systems. Transport Res E: Log 88:52-75. https://doi.org/10.1016/j. tre.2016.02.002

Zhou X, Gao Y, Ren J, Guo H (2015) Multi-objective site selection model and algorithm for remanufacturing reverse logistics under government subsidy. Systems Engineering-Theory \& Practice (in Chinese) 35:1996-2003

Publisher's note Springer Nature remains neutral with regard to jurisdictional claims in published maps and institutional affiliations. 